\title{
Bridging the Chasm: A Comparison of the Army's 1997 and 2012 Doctrinal Planning Processes
}

\author{
A Monograph \\ by \\ MAJ David M. Ike \\ US Army

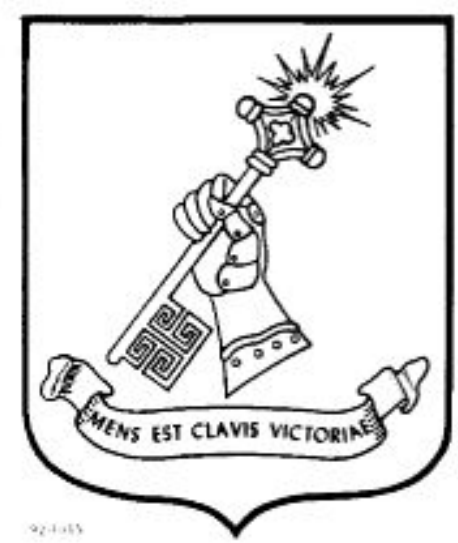 \\ School of Advanced Military Studies \\ United States Army Command and General Staff College \\ Fort Leavenworth, Kansas \\ 2014-02
}




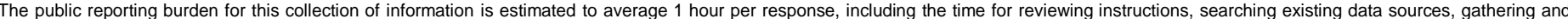

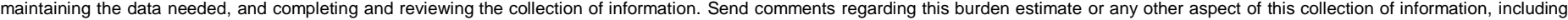

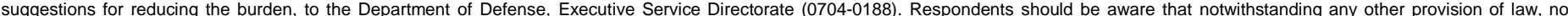
person shall be subject to any penalty for failing to comply with a collection of information if it does not display a currently valid OMB control number.

PLEASE DO NOT RETURN YOUR FORM TO THE ABOVE ORGANIZATION.
1. REPORT DATE $(D D-M M-Y Y Y Y)$ 2. REPORT TYPE
$04-12-2014$
SAMS Monograph
3. DATES COVERED (From - To)

4. TITLE AND SUBTITLE

Bridging the Chasm: A Comparison of the Army's 1997 and 2012 Doctrinal Planning

Processes

5b. GRANT NUMBER

5c. PROGRAM ELEMENT NUMBER
6. AUTHOR(S)

David M. Ike
Major, United States Army

\section{5a. CONTRACT NUMBER}

5e. TASK NUMBER

5f. WORK UNIT NUMBER

7. PERFORMING ORGANIZATION NAME(S) AND ADDRESS(ES)

U.S. Army Command and General Staff College

ATTN: ATZL-SWD-GD

100 Stimson Ave

Fort Leavenworth, KS 66027-2301

9. SPONSORING/MONITORING AGENCY NAME(S) AND ADDRESS(ES)

10. SPONSOR/MONITOR'S ACRONYM(S)

11. SPONSOR/MONITOR'S REPORT NUMBER(S)

12. DISTRIBUTIONIAVAILABILITYSTATEMENT

Approved for public release, distribution is unlimited

\section{SUPPLEMENTARY NOTES}

\section{ABSTRACT}

Between 1997 and 2001, critics stated that the Military Decision-Making Process (MDMP) did not account for all variables on the battlefield and yielded decisions too slowly. Soldiers' experiences during the early years of Operation Enduring Freedom (OEF) and Operation Iraqi Freedom (OIF) served as a catalyst for necessary doctrinal changes. An examination of the doctrinal updates as of 2012 reveals the integration of alternate decision-making models to accommodate different situational requirements. Army planning doctrine now provides a framework for a more comprehensive understanding of conditions, emphasizes anticipation of change, and outlines a technique to make decisions faster than it did in 1997. However, units misunderstand key facets of the process and misuse them, but are showing signs of proper incorporation. It is difficult to evaluate the effectiveness of Army education, but recent Command and General Staff Officer Course (CGSOC) classes demonstrated an interest in the process. Recommendations to enhance use of the planning process include creating incentive for analysis and anticipation during planning, improving unit internal education of the planning process, emphasizing continued iteration of the planning process, and areas of future study.

\section{SUBJECT TERMS}

Decision-making, battlespace, operational environment, operational variables, mission variables, frame, reframe, anticipation, rapid decisionmaking, complexity theory, naturalistic decision-making, emergent strategy, rational choice, recognition primed decision-making, decision-point tactics, integration, education.

\begin{tabular}{|c|c|c|}
\hline \multicolumn{3}{|c|}{ 16. SECURITY CLASSIFICATION OF: } \\
\hline a. REPORT & b. ABSTRACT & c. THIS PAGE \\
Unclassified & Unclassified & Unclassified \\
\hline
\end{tabular}

\section{LIMITATION OF ABSTRACT}

UU
18. NUMBER $19 a$. NAME OF RESPONSIBLE PERSON OF PAGES

49 19b. TELEPHONE NUMBER (Include area code) 


\section{Monograph Approval Page}

Name of Major David M. Ike

Candidate:

Monograph Title: $\quad$ Bridging the Chasm: A Comparison of the Army's 1997 and 2012 Doctrinal Planning Processes

Approved by:

Peter J. Schifferle, PhD , Monograph Director

James W. MacGregor, COL , Seminar Leader

, Director, School of Advanced Military Studies

Henry A. Arnold III, COL

Accepted this $4^{\text {th }}$ day of December 2014 by:

, Director, Graduate Degree Programs

Robert F. Baumann, PhD

The opinions and conclusions expressed herein are those of the student author and do not necessarily represent the views of the US Army Command and General Staff College or any other government agency. (References to this study should include the foregoing statement.) 


\begin{abstract}
Bridging the Chasm: A Comparison of the Army’s 1997 and 2012 Doctrinal Planning Processes, by MAJ David M. Ike, US Army, 49 pages.

Between 1997 and 2001, critics stated that the Military Decision-Making Process (MDMP) did not account for all variables on the battlefield and yielded decisions too slowly. Soldiers'

experiences during the early years of Operation Enduring Freedom (OEF) and Operation Iraqi Freedom (OIF) served as a catalyst for necessary doctrinal changes. Doctrinal updates between 2005 and 2012 addressed these concerns through the advent of Army Design Methodology (ADM) and the Rapid Decisionmaking and Synchronization Process (RDSP). In addition, the Decision Support Template (DST) and accompanying Decision Support Matrix (DSM) received renewed emphasis.

An examination of the doctrinal updates reveals the integration of alternate decision-making models to accommodate different situational requirements. Army planning doctrine now provides a framework for a more comprehensive understanding of conditions, emphasizes anticipation of change, and outlines a technique to make decisions faster than it did in 1997. However, the frameworks require planners to understand and use them properly. Army units misunderstand key facets of the process and misuse them, but are showing signs of proper incorporation. Similarly, it is difficult to evaluate the effectiveness of Army education, but the most recent Command and General Staff Officer Course (CGSOC) classes demonstrated an interest in the process.

Recommendations to enhance use of the planning process include creating incentive for analysis and anticipation during planning, improving unit internal education of the planning process, emphasizing continued iteration of the planning process, and areas of future study.
\end{abstract}




\section{Contents}

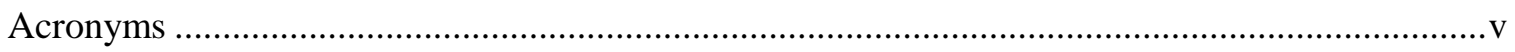

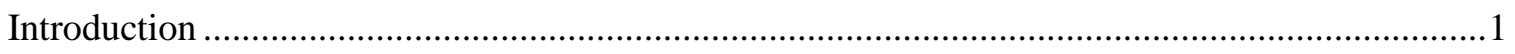

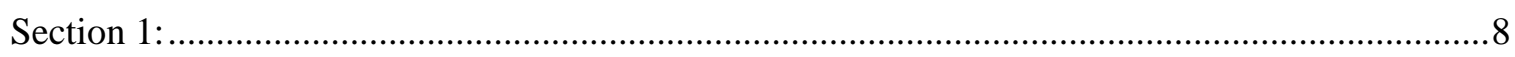

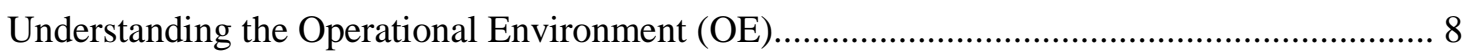

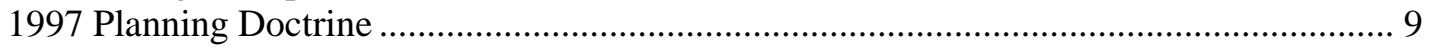

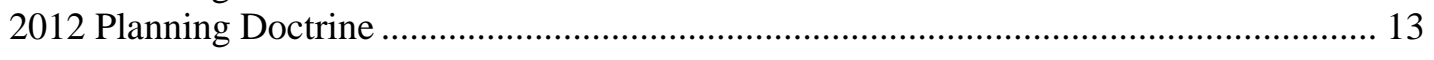

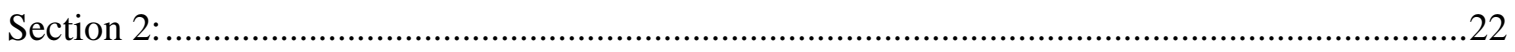

Decision Support Template (DST) and Rapid Decisionmaking and Synchronization Process

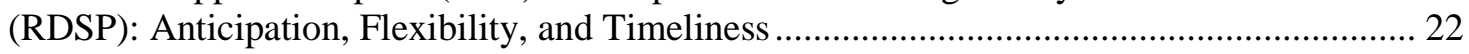

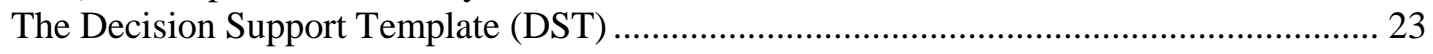

Rapid Decisionmaking and Synchronization Process (RDSP) ........................................ 26

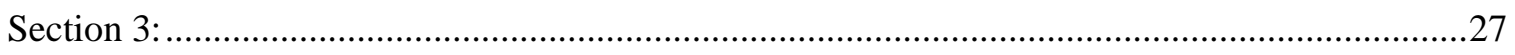

Alternate Decision-Making Models and their Integration into Doctrine ................................ 27

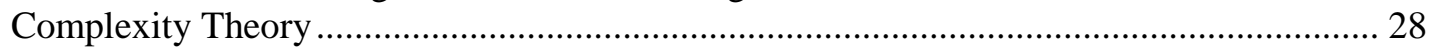

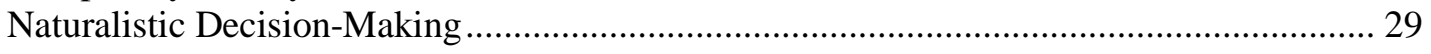

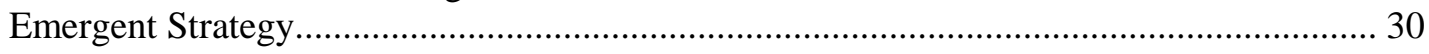

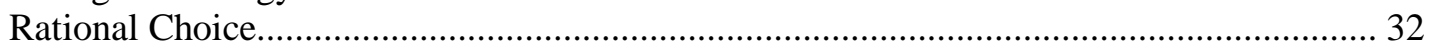

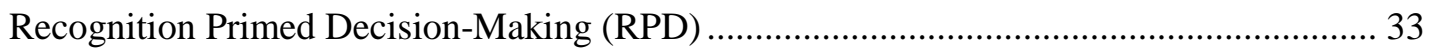

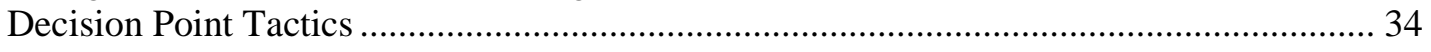

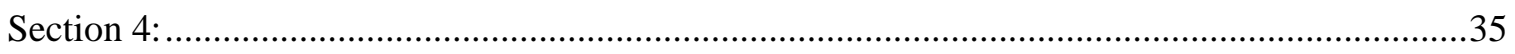

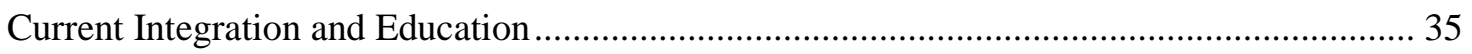

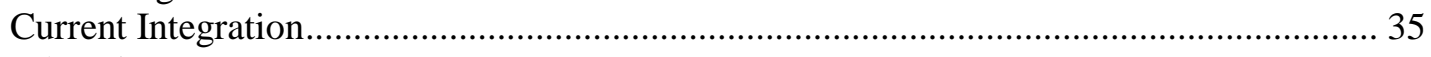

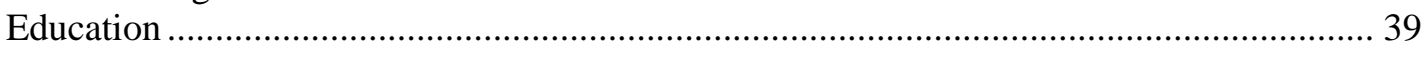

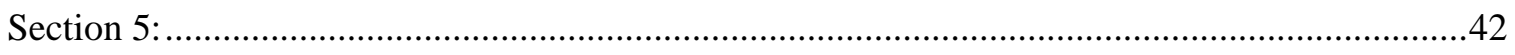

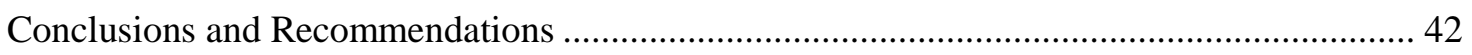

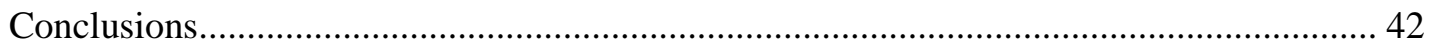

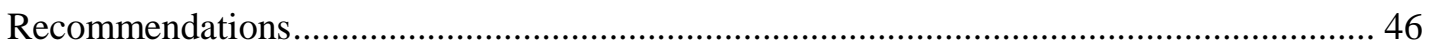

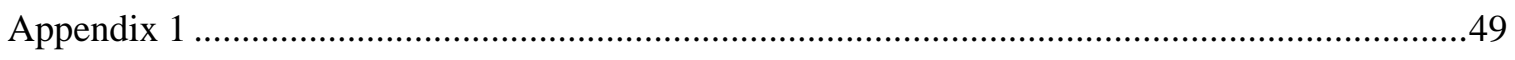

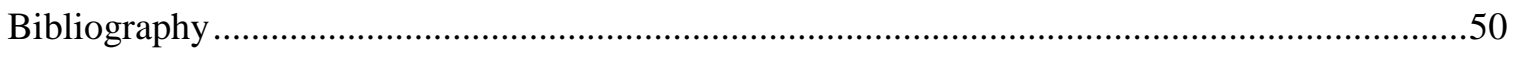




\section{Acronyms}

\begin{tabular}{|c|c|}
\hline ADM & Army Design Methodology \\
\hline $\mathrm{ADP}$ & Army Doctrine Publication \\
\hline ADRP & Army Doctrine Reference Publication \\
\hline CCIR & Commander's Critical Information Requirements \\
\hline CGSOC & Command and General Officer Course \\
\hline COA & Course of Action \\
\hline COL & Colonel \\
\hline COIN & Counterinsurgency \\
\hline DP & Decision Point \\
\hline DSM & Decision Support Matrix \\
\hline DST & Decision Support Template \\
\hline FM & Field Manual \\
\hline IPB & Intelligence Preparation of the Battlefield \\
\hline IR & Information Requirement \\
\hline JP & Joint Publication \\
\hline LTC & Lieutenant Colonel \\
\hline MAJ & Major \\
\hline MCTP & Mission Command Training Program \\
\hline MDMP & Military Decision-Making Process \\
\hline METT-TC & $\begin{array}{l}\text { Mission, Enemy, Terrain, Troops Available, Time Available, and Civil } \\
\text { Considerations }\end{array}$ \\
\hline MI & Military Intelligence \\
\hline NAI & Named Area of Interest \\
\hline $\mathrm{OE}$ & Operational Environment \\
\hline OEF & Operation Enduring Freedom \\
\hline OIF & Operation Iraqi Freedom \\
\hline
\end{tabular}


PMESII-PT Political, Military, Economic, Social, Information, Infrastructure, Physical Environment, and Time

RDSP Rapid Decisionmaking and Synchronization Process

RPD Recognition Primed Decision-Making

SAMS School of Advanced Military Studies

SOP Standard Operating Procedure

TAI Targeted Area of Interest

TLP Troop Leading Procedures

TPL Time Phased Lines

WFX Warfighter Exercises 


\section{Tables}

Table 1: Comparison of FM 101-5 (1997) and ADRP 5-0 (2012) methodologies for understanding conditions. 


\section{Introduction}

In preparing for battle I have always found that plans are useless, but planning is indispensable.

—General of the Army Dwight D. Eisenhower ${ }^{1}$

During the late 1980’s and early 1990’s, US Army units performed well in maneuver battles with conventional opponents. During Operation Just Cause (Panama, 1989), the Army contributed to the surrender of Manuel Noriega in just over two weeks. Army units achieved their objectives within 100 hours during Operation Desert Storm (Iraq, 1991). Although forces never executed the conventional invasion for Operation Uphold Democracy (Haiti, 1994 - 1995), the sheer threat of force helped persuade the Haitian leaders to step down. One could say these operations went as well as planned. At the time, the 1984 Field Manual (FM) 101-5, Staff Organization and Operations was the primary manual for US Army planning. Based on Cold War threats, FM 101-5 (1984) seemed to address a predictable, conventional fight well. However, it did not do so well when battlefield conditions changed or when soldiers faced something other than a conventional opponent.

The peacekeeping Operation Restore Hope (Somalia, 1992 - 1993) inspired changes to doctrine to account for conditions besides a conventional opponent on an open battlefield. Later, the US peacekeeping contingent within the Implementation Force (Bosnia, 1995 - 1996) and the Stabilization Force (Bosnia, began in1996) reinforced the same lessons. Planning doctrine seemed insufficient when units faced changing dynamics on the battlefield or considerations beyond a conventional foe. Consequently, the Army updated planning doctrine in 1997 to begin to account for concerns in addition to a conventional foe.

${ }^{1}$ Army Doctrine Reference Publication (ADRP) 5-0, The Operations Process (Washington, DC: Government Printing Office, 2012), 2-2. 
The 1997 FM 101-5, Staff Organization and Operations became the primary guide for planning. It listed the Military Decision-Making Process (MDMP) as the primary method for problem solving at battalion and above. It also referenced the Troop Leading Procedures (TLP) for company and below, but another manual defined TLP. ${ }^{2}$ FM 101-5 (1997) defined MDMP as a seven-step process: Receipt of Mission, Mission Analysis, Course of Action (COA) Development, COA Analysis, COA Comparison, COA Approval, and Orders Production. FM 101-5 (1997) advocated MDMP as “a single, established, and proven analytical process.”3

FM 101-5 (1997) did not satisfy critics. Critics stated that MDMP was inadequate. Research scientist Gary Klein had previously stated that MDMP was cumbersome and lacked flexibility. He recommended a more intuitive model that he had developed. ${ }^{4}$ In 1997, the US Army Research Institute for Behavioral and Social Sciences commissioned Klein to examine how his intuitive decision-making model was applicable to Army operations. ${ }^{5}$

In October 2000, in a School of Advanced Military Studies (SAMS) monograph, Major (MAJ) Wilson Shoffner stated MDMP was too rigid and did not allow for adaptation under rapidly changing battlefield conditions. He clarified that MDMP produced one plan tested against one set of conditions and was thus fundamentally inappropriate. Shoffner advocated intuitivebased theories that gave a commander greater flexibility and generated decisions more rapidly.

${ }^{2}$ Field Manual (FM) 7-8, Infantry Rifle Platoon and Squad (Washington, DC: Government Printing Office, 1992), 2-3.

${ }^{3}$ Field Manual (FM) 101-5, Staff Organization and Operations (Washington, DC: Government Printing Office, 1997), 5-1.

${ }^{4}$ Gary A. Klein, “Strategies of Decision Making,” Military Review (May 1989), 56.

${ }^{5}$ Klein Associates, Inc., Making Decisions in Natural Environments (Alexandria: US Army Research Institute, 1997), 7. 
The tradeoff, however, was that intuitive-based theories required a more comprehensive understanding of an environment. ${ }^{6}$

In 2001, Colonel (COL) Christopher Paparone surveyed the progression of Army planning doctrine from 1910 to 1997. His recommendations for future doctrine echoed two of Shoffner's concerns. He called for “equal weight to [the] more multidimensional aspects [of planning]" and increases to the flexibility and speed of MDMP. ${ }^{7}$ He joined the other critics who stated that MDMP did not account for all variables on the battlefield and yielded decisions too slowly. As a result, it was inadequate, cumbersome, and inflexible.

By 2012, the Army had addressed the 1997 to 2001 criticisms through doctrinal updates. The current planning process allows for more flexible plans and more timely decisions than it did in 1997. It achieves this is by providing a framework for a more comprehensive understanding of conditions, emphasizing anticipation of change, and outlining a technique to make decisions faster.

The Army Doctrinal Reference Publication (ADRP) 5-0, The Operations Process (2012), defines the Army's doctrinal planning process and includes three methodologies: Army Design Methodology (ADM), Military Decision-Making Process (MDMP), and Troop Leading Procedures (TLP). ${ }^{8}$ ADM provides a framework for a comprehensive understanding of the operational environment and for developing a conceptual approach for problem solving. MDMP provides a framework for detailed planning. Although MDMP has not changed fundamentally

${ }^{6}$ MAJ Wilson A. Shoffner, The Military Decision-Making Process: Time For A Change. (SAMS Monograph, US Army Command and General Staff College, 2000), 1 and 2. As of this publication Brigadier General (BG) Wilson A. Shoffner was serving as Deputy Chief of Staff, G3/5/7 at US Army Training and Doctrine Command (TRADOC).

${ }^{7}$ COL Christopher Paparone, "US Army Decisionmaking: Past, Present and Future," Military Review (July-August 2001), 52.

${ }^{8}$ ADRP 5-0 (2012), 2-4. 
from the 1997 model, one of its components, the Decision Support Template (DST), received renewed emphasis. In addition, the Rapid Decisionmaking and Synchronization Process (RDSP) outlines a technique for making decisions rapidly. Collectively, these three refinements to planning doctrine - the advent of new two methodologies, ADM and RDSP, and the renewed emphasis on the DST - address the 1997 to 2001 criticisms.

Although TLP remain part of the Army's doctrinal planning process, they are not applicable to this investigation. This investigation concerns planning that involves commanders and staffs at battalion level and above. TLP do not require staffs and apply to company level and below. ${ }^{9}$ Therefore, this monograph focuses on ADM and MDMP.

Given the three refinements to doctrine, the planning process within ADRP 5-0 (2012) raises a question for examination. Compared to the FM 101-5 (1997) process, how does the current planning process allow for flexible plans and timely decisions under rapidly changing conditions in the operational environment? The answer comes through an examination of four supplemental questions, each with sub-components of its own.

The first question is how does the current planning process enable a more comprehensive understanding of the operational environment (OE) as compared to 1997 processes? Section 1 compares doctrinal methodologies for understanding conditions from FM 101-5 (1997) to those in ADRP 5-0 (2012). ${ }^{10}$ The comparison has four components. The first component compares the commander's doctrinal role in planning between the respective manuals. The second compares the doctrinal frameworks for understanding conditions. The third compares the doctrinal frameworks used to address the impact of tangible and intangible variables on the environment. The fourth compares the doctrinal frameworks used to translate the variables into a usable

${ }^{9}$ ADRP 5-0 (2012), 2-14.

${ }^{10}$ The comparison of frameworks for understanding conditions focuses on doctrinal guidance and does not consider actual techniques that commanders and staffs may have used. 
analysis. ADM serves as a framework for a more comprehensive understanding of the OE. If used as intended, ADM makes commanders more cognizant of complex conditions.

The second question is how does the current planning process enable commanders to anticipate change and develop and implement solutions in a timely manner? Section 2 examines the DST and RDSP which facilitate flexibility and timely decisions. The section first describes FM 101-5 (1997) lack of emphasis on the DST and lack of clarity in rapid decision-making. Second is a description of the DST and accompanying Decision Support Matrix (DSM). An explanation of how ADRP 5-0 (2012) provides adequate emphasis on the DST and the integration of Commander's Critical Information Requirements (CCIR) follows. The section closes with an explanation of how the RDSP provides a doctrinal framework for timely decision-making. ${ }^{11}$

The third question considers whether there is a better process for developing plans that are more flexible and suitable for making timely decisions. Section 3 examines alternate decisionmaking models. Section 3 first presents complexity theory, a concept that, while not a decisionmaking model, nonetheless contributes to understanding an environment. Decision-making models include naturalist decision-making, emergent strategy, rational choice, recognition-prime decision-making, and decision point tactics. The Army has integrated each of these theories and models into ADRP 5-0 (2012).

The fourth question is do commanders and staffs understand the current planning process? Given the fact that there is very little research on this topic, this monograph includes several structured interviews with Mission Command Training Program (MCTP) observercontrollers, staff officers, and Command and General Staff Officer’s Course (CGSOC) instructors. The author of this paper received informed consent for all interviews (see Appendix 1). Section 4 examines application and education of the current planning process. First is an

${ }^{11}$ Like Section 1, the explanations focus on doctrinal guidance and do not consider actual techniques commanders and staffs may have used. 
examination of how units apply the planning process during Warfighter Exercises (WFX) at the MCTP. Under pressure to produce an executable plan, units often abbreviate understanding of the OE and misuse the DST due to inappropriate habits developed over a decade of counterinsurgency (COIN) operations. However, there is evidence units are beginning to integrate the doctrinal planning process. Second is an examination of the planning process education at CGSOC. ${ }^{12}$ The CGSOC curriculum includes ADM, MDMP, and RDSP. However, the curriculum has a high proportion allocated to MDMP. Furthermore, it is difficult to measure the curriculum's effectiveness. Separately, instructors state that students in the most recent classes demonstrate a genuine interest in the process.

Having answered the four supplemental questions, Section 5 presents an evaluation of the current planning process according to the following criteria. First, does the process adequately incorporate the complexities of the OE? Second, does the process account for the changing nature of the OE? Third, does the process result in timely decisions? Fourth, is the method appropriate at the operational and the tactical level? Fifth, can a curriculum teach the process? Sixth, can individuals learn the process? These six evaluation questions provide a comprehensive list to evaluate this author's supplemental four questions. They are a modified version of Shoffner's 2000 criteria. $^{13}$

${ }^{12}$ The author acknowledges that the Advanced Military Studies Program (AMSP) at the School of Advanced Military Studies (SAMS) also addresses the planning process. The Army designed AMSP as a supplemental program to address doctrinal deficiencies at CGSOC. However, a comparison of those curriculums is beyond the scope of this monograph.

${ }^{13}$ Shoffner's 2000 criteria were on pages 2 and 3 of his monograph, “(a) Does the method adequately incorporate the complexities of the battlefield? (b) Does the method result in timely decisions? (c) Does the method account for the changing nature of the battlefield? (d) Is the method appropriate at the tactical level? (e) Can the method be taught? (f) Can the method be learned?” The author of this paper made three modifications to Shoffner's criteria. First, the term "operational environment" (OE) replaced the word "battlefield" to stay consistent with ADRP 5-0 (2012) terminology. Second, the author reversed the order of Shoffner's (b) and (c) to demonstrate the structure of the supplemental questions more effectively. The third pertains to 
Key definitions for the evaluation include flexibility and timeliness. This author defines flexibility according to the Tenets of Unified Land Operations in Army Doctrine Publication (ADP) 3-0, Operations (2011). This manual defines flexibility as, "the capability to act quickly across the range of military options.” Its definition of adaptability supplements this by saying, “Army leaders accept that no prefabricated solutions to tactical or operational problems exist. Army leaders must adapt their thinking, their formations, and their employment techniques to the specific situation they face.” ${ }^{14}$ There is no known Department of Defense definition for timeliness. Therefore, this author defines it as providing adequate time for subordinate units, two levels down, to react to a decision, plan for its implementation, and execute it in the face of a thinking, proactive adversary. ${ }^{15}$

The investigation concludes that the current planning process allows for more flexible plans and more timely decisions than it did in 1997. It achieves this is by providing a framework for a more comprehensive understanding of conditions, emphasizing anticipation of change, and outlining a technique to make decisions faster. However, the doctrinal tools are only useful if a commander and staff understand them and are willing to incorporate them into planning.

criteria (d), where the author considers whether the process is appropriate at both the tactical and operational levels. Different levels require different planning considerations. The author seeks to determine whether the 2012 planning process accommodates different requirements. Page vii of FM 101-5 (1997) states that 1997 planning doctrine was not intended for echelons above the operational level. Therefore, the author considers the strategic level beyond the scope of this examination.

${ }^{14}$ Army Doctrine Publication (ADP) 3-0, Unified Land Operations (Washington, DC: Government Printing Office, 2011), 7 and 8.

15 The author based the definition of timeliness on the definition of "tempo" from ADRP 3-0 (2012), 4-7. ADRP 3-0 (2012) defines tempo as, "the relative speed and rhythm of military operations over time with respect to the enemy.” The definition further discusses using tempo to maintain initiative over the enemy. Commanders can leverage tempo to "overwhelm the enemy's ability to counter friendly actions" and "act quickly to control events and deny the enemy positions of advantage.” 
Recommendations to enhance use of the planning process include creating incentive for analysis and anticipation during planning, improving unit internal education of the planning process, emphasizing continued iteration of the planning process, and areas of future study.

\section{Section 1:}

\section{Understanding the Operational Environment (OE)}

In order to develop an adequate plan, one must first understand their environment. Shoffner cited a study that foresaw structural and interactive complexities coupled with ambiguity, uncertainty, and unpredictability in the twenty-first century. ${ }^{16}$ One may argue that simply researching a given problem in extensive detail will eventually reveal its source and facilitate a solution. However, another experiment found that more information "saturates the human decision-making system and freezes action.”" ${ }^{17}$ The issue did not seem to be a matter of information volume but rather selecting information relevant to decision-making.

The Army has developed tools to help decipher relevant information. These tools are significantly more comprehensive than their predecessors. FM 101-5 (1997) methods for understanding battlefield conditions were Battlefield Visualization and Intelligence Preparation of the Battlefield. However, these did not adequately account for intangible variables on the battlefield, such as economic conditions and social interactions. ADRP 5-0 (2012) includes more comprehensive tools to address ambiguity, uncertainty, and complex interactions. These include the Commander Activities, adoption of the term “operational environment” and the corresponding operational variables, and, finally, Army Design Methodology (ADM).

${ }^{16}$ Shoffner, MDMP, 14 and 15.

${ }^{17}$ LTC John Antal, "It's Not the Speed of the Computer that Counts! The Case for Rapid Battlefield Decision-making,” Armor (May-June 1998), 13, originally found in Shoffner, 14. 


\section{Planning Doctrine}

Battlefield Visualization, Battlespace, and the Battlefield

In 1997, commanders “battlefield visualization” drove the Army’s planning process. FM 101-5 (1997) defined "battlefield visualization" as "the process whereby the commander develops a clear understanding of his current state with relation to the enemy and environment, envisions a desired end state, and then visualizes the sequence of activities that will move his force from its current state to the end state.”18 This concept enabled the commander to imagine how the unit would array and operate to achieve the desired end state. The commander first had to understand what he needed to effect in terms of physical space and enemy forces. The Army defined such space as "battlespace."

The term "battlespace” referred to the elements within physical space that the commander sought to influence. The 1997 version of Field Manual (FM) 101-5-1: Operational Terms and Graphics defined "battlespace” as:

The conceptual physical volume in which the commander seeks to dominate the enemy. It expands and contracts in relation to the commander's ability to acquire and engage the enemy, or can change as the commander's vision of the battlefield changes. It encompasses three dimensions and is influenced by the operational dimensions of time, tempo, depth, and synchronization. It is not assigned by a higher commander nor is it constrained by assigned boundaries. ${ }^{19}$

This definition suggested that the overall purpose of operations was to dominate the enemy. It encompassed numerous elements that the commander had to consider, both concrete and abstract, to achieve that goal. It did not bind a unit to specific space but enabled a unit to adjust to the changing conditions. This definition seems to have enabled a commander to use ways and means as necessary to achieve a desired end state without unnecessary constraints or limitations.

${ }^{18}$ FM 101-5 (1997), 1-3.

${ }^{19}$ Field Manual (FM) 101-5-1, Operational Terms and Graphics (Washington, DC: Government Printing Office, 1997), 1-18. 
However, the Army used the term "battlefield" instead of "battlespace” in reference to specific geographic space, processes, and staff responsibilities. The Army did not define the term "battlefield,” but "battlefield visualization” drove the planning process and the "battlefield framework” was a key component.

To assist in planning, the "battlefield framework" included specific details. The Army defined it as the "overall structure of the battlefield which, at the tactical level of war, consists of four interrelated concepts: area of interest, battlespace, area of operations, and battlefield organization.” FM 101-5-1 (1997) further clarified that the commander would array forces in time, space, and purpose according to the enemy situation. He or she would do this under full consideration of the four interrelated concepts. First, area of interest was where a unit would gather intelligence on enemy forces or "characteristics of the battlefield" that shaped tactical operations. Second was battlespace, which the previous paragraph described. Third, area of operations referred to the boundaries where a commander had authority and responsibility. Finally, battlefield organization was how a commander arrayed and synchronized "battlefield activities throughout the area of operations to accomplish the simultaneous operations of deep, close, and rear." ${ }^{20}$

These definitions emphasized tangible variables, such as terrain or geographical space, and immediate, tactical-level operations against an enemy. Furthermore, although the definition of "battlespace” seemed to encourage consideration of intangible variables, FM 101-5 (1997) did not give them much emphasis. ${ }^{21}$ FM 101-5 (1997) primarily used “mission variables,” including: mission, enemy, terrain, troops available, and time available (METT-T). These suggested a focus on tangible variables and pertained mainly to the immediate, tactical mission at-hand. Intangible

${ }^{20}$ FM 101-5-1 (1997), 1-10 and 1-18.

${ }^{21}$ FM 101-5 (1997). 
variables, such as civil considerations, did not receive equal emphasis. Thus, the inputs into developing a mission pertained mainly to tangible variables at the tactical level. Units understood these variables through Intelligence Preparation of the Battlefield (IPB).

Intelligence Preparation of the Battlefield (IPB)

Intelligence Preparation of the Battlefield (IPB) was the primary method of analyzing the battlefield. FM 101-5 (1997) defined IPB as “a systematic, continuous process of analyzing the effects of the environment on the unit.”22 IPB took place during Mission Analysis, Step 2 of MDMP. The unit intelligence officer (G2/S2), who FM 101-5 (1997) described as "the principal staff officer for all matters concerning military intelligence (MI)," led IPB. ${ }^{23}$ The entire staff contributed.

The IPB had four outputs. First was identification of gaps in intelligence and an understanding of battlespace characteristics that could influence friendly or threat forces. Second was evaluation of terrain, weather, and infrastructure. Third was evaluation of the threat's organization and operational tendencies. Fourth, the G2/S2 would combine these three elements to determine how the threat would most likely operate within a specific environment. These were enemy COAs. ${ }^{24}$ While FM 101-5 (1997) articulated the essence of IPB, there was an entire manual dedicated solely to it.

FM 34-130, Intelligence Preparation of the Battlefield (1994) specified how to conduct IPB. What is notable about FM 34-130 (1994) is that it also seemed to emphasize tangible variables, such as terrain and weather. For example, FM 34-130 (1994) went into detail on how a

${ }^{22}$ FM 101-5 (1997), 5-6.

${ }^{23}$ FM 101-5 (1997), 4-10.

${ }^{24}$ FM 101-5 (1997). 
dense forest, steep mountains, or lakes and rivers could affect maneuver. FM 34-130 (1994) did not seem to do the same for intangible variables, such as the population's sentiment, local customs, or religious practices.

On the other hand, FM 34-130 did not completely disregard intangibles. There was a section titled "Analysis of Other Characteristics of the Battlefield” and the manual outlined various scenarios to demonstrate how tangible and intangible variables affected a given mission. ${ }^{25}$ However, identification and consideration of such intangible variables seemed directed toward other staff officers. FM 101-5 (1997) tasked the G2/S2 to coordinate with the civil-military officer (G5/S5) for issues regarding civilians. It seemed that commanders would consider intangible variables as necessary, but only so far as the intelligence and civil-military officers identified them.

One could argue the same was true for other facets of planning, such as the fire-support officer analyzing fires or the engineer analyzing mobility. However, the problem was that doctrine emphasized the impact of tangible variables. The METT-T variables were the baseline considerations for planning, but there was no equivalent for intangibles. For example, the sections of FM 34-130 (1994) regarding terrain and weather analysis took nearly eighteen pages whereas the "Analysis of Other Characteristics of the Battlefield” section barely took three. ${ }^{26}$ It seemed that consideration of intangible variables was in its infancy.

IPB had a crucial role in describing the "battlefield" and its effects, but it seemed somewhat limited. It was definitely a useful tool to evaluate variables relevant to the mission. Its execution during the Step 2 of MDMP was adequate because it created the necessary understanding of ground conditions in order to achieve the desired end state. However, the

${ }^{25}$ Field Manual (FM) 34-130, Intelligence Preparation of the Battlefield (Washington, DC: Government Printing Office, 1994), 2-26 and Chapter 3.

${ }^{26}$ FM 34-130 (1994). 
apparent focus on tangible variables lead to an incomplete understanding of environmental conditions.

Events that transpired in the years following the 1997 to 2001 criticisms helped foster necessary change. By 2003, the US Army was involved in Operation Enduring Freedom (OEF) and Operation Iraqi Freedom (OIF). During those operations, US soldiers continued to experience a myriad of dynamics on the "battlefield" that had effects beyond the immediate tactical situation. Regular interaction with the populace and consideration of political factors fostered a change to doctrine. Operations during the 1990's revealed the need to consider a much broader scope of intangible variables than traditional IPB covered. The early years of OEF and OIF served as a catalyst to propel emphasis of intangible variables equal to that of tangible variables. Unfortunately, there was no IPB-like framework to identify and consider intangible variables.

\section{Planning Doctrine}

ADRP 5-0 (2012) planning doctrine expands beyond that of FM 101-5 (1997). Each 2012 element is more comprehensive than its 1997 counter-part, although each still bears principles from its predecessor. The commander still drives the process, but “commander activities” replaced his “battlefield visualization.” The “operational environment” (OE) replaced "battlespace” and the "operational variables” compliment the “mission variables.” Finally, Army Design Methodology (ADM) complements planning generally and Intelligence Preparation of the Battlefield (IPB) specifically by providing a framework to consider the impact of complex, intangible variables.

\section{Commander Activities}

Commander activities encompass everything the commander must do to drive the planning process. These activities include “understand,” “visualize,” “describe,” “direct,” “lead,” 
and "assess." 27 These activities are interrelated and most of them have sub-components of their own. ADM and IPB yield analysis of the environment, which helps the commander "understand" the current state. Once a commander understands the environment, he then “visualizes” a desired end state and begins to consider potential solutions to existing problems. ADM provides a framework to identify the desired future state. Next, the commander “describes” how he visualizes an operation. This description comes through a “commander’s intent,” “planning guidance,” “commander’s critical information requirements” (CCIR), and “essential elements of friendly information.” ${ }^{28}$ A commander “directs” through commander’s intent and specific orders.

Although the first four components bear striking resemblance to "battlefield visualization,” the incorporation of “lead” and “assess” into doctrine separate commander activities. "Lead" and "assess" encompass the previous four components. To "lead" is to "provide purpose, direction, and motivation to subordinate[s].”29 “Assessing” is a continuous process where a commander constantly determines whether the plan is appropriate. A commander "leads" and “assesses” by providing guidance as necessary and directing change as required.

A commander provides guidance and direction through formal and informal methods. For example, regarding formal methods, a commander issues initial guidance early in the planning process and receives briefs throughout as the staff develops the plan. The commander provides feedback during these briefs to ensure the staff is developing the plan according to his understanding and visualization. The staff keeps the commander abreast of new developments and the commander determines whether to adjust and directs the staff accordingly. Once a plan is under execution, the commander and staff continue to monitor the situation. As the situation

${ }^{27}$ ADRP 5-0 (2012), 1-3.
${ }^{28}$ ADRP 5-0 (2012), 1-5.
${ }^{29}$ ADRP 5-0 (2012), 1-6. 
develops, the commander continues to provide direction to ensure the unit achieves the desired end state. Regarding informal methods, ADRP 5-0 encourages "collaboration and dialogue” throughout the process. Such dialogue is candid and often takes place in forums outside of formal briefings. During dialogue, commanders and subordinates freely express opinions and ideas based on perception and experience. ${ }^{30}$

Operational Environment (OE)

The OE is more comprehensive than the "battlefield.” Similarly, the “operational variables” provide a framework to consider the impact of tangible and intangible variables within the OE. The term “operational environment” existed in 1997, but FM 101-5-1 (1997) simply referenced joint doctrine. Joint Publication (JP) 1-02, Department of Defense Dictionary of Military and Associated Terms defined the OE as "a composite of the conditions, circumstances, and influences that affect the employment of capabilities and bear on the decisions of the commander.”31

A comparison of the "battlefield” and “operational environment” reveals subtle but significant differences. Although the Army never defined "battlefield," "battlespace” was a component of the "battlefield framework." The definition of "battlespace” started with “conceptual physical volume in which the commander seeks to dominate the enemy.” The definition followed with "it expands and contracts in relation to the commander's ability to acquire and engage the enemy, or can change as the commander's vision of the battlefield

\footnotetext{
${ }^{30}$ ADRP 5-0 (2012), 1-10 and 1-11.

${ }^{31}$ Joint Publication (JP) 1-02, Department of Defense Dictionary of Military and Associated Terms (Washington, DC: Government Printing Office, 1994), 275.
} 
changes." 32 These excerpts corroborate the previous discussion of the "battlefield's" focus on the tangible METT-T factors and the immediate tactical situation. Furthermore, the latter excerpt seemed to suggest that "battlespace” was a bottom-up process where the commander defined it for himself according to the enemy.

The definition of "battlespace” also fell short of the OE's “composite of conditions." If a commander defined "battlespace" relative to the effects he needed to impart on the enemy, then location of the enemy force and its resources influenced the definition. A commander would focus operations where he needed to achieve effects, such as locations of enemy personnel, lines of communication, or supply caches. A commander could adjust the "battlespace" to accommodate for those locations and desired effects; the "battlespace" was where the commander pursued the enemy.

By contrast, the “composite of conditions” was not bound to an enemy location or operation. The "composite” accounted for the "conditions, circumstances, and influences that affect the employment of capabilities and bear on the decisions of the commander.” This definition did not specify engaging the enemy. By including broad concepts like "conditions, circumstances, and influences,” it fostered consideration of variables beyond the enemy pursuit. The enemy pursuit certainly "[affected] the employment of capabilities and [bore] on the decisions of the commander," but so did the population's sentiment, local customs, and religious practices.

The Army officially adopted the term "operational environment” to replace "battlefield” in 2007. ${ }^{33}$ The Army adopted the JP 1-02 (1994) definition of “operational environment” and the

${ }^{32}$ FM 101-5-1 (1997), 1-18.

${ }^{33}$ Combined Arms Directorate, Army Doctrine Update (Fort Leavenworth, KS: US Army Combined Arms Center, 2007). 
2012 Army Doctrine Reference Publication (ADRP) 1-02, Operational Terms and Military Symbols contains that definition. ${ }^{34}$ Adoption of this term and definition placed greater emphasis on the intangible variables that traditional IPB and mission variables did not seem to emphasize. The Army did not discard the 1997 mission variables; it combined tangibles and intangibles for a comprehensive framework.

In 2008, the Army created “operational variables” and “mission variables” as a framework to consider a range of tangible and intangible variables within the OE. "Operational variables" were defined as "those broad aspects of the environment, both military and nonmilitary, that may differ from one operational area to another and affect campaigns and major operations... [they] describe not only the military aspects of an operational environment but also the population's influence on it.”35 These variables included political, military, economic, social, information, infrastructure, physical environment, and time (PMESII-PT). The key point about these variables is that they emphasized human interaction and influence over an area. This further enabled planners to consider effects beyond limited physical descriptions of the environment.

Doctrine defined “mission variables” as "those aspects of the operational environment that directly affect a mission. They outline the situation as it applies to a specific Army unit.” Like METT-T, “mission variables” included mission, enemy, terrain and weather, troops and support available, and time available, but added civil considerations for METT-TC. ${ }^{36}$ Thus, the Army created a framework to consider variables beyond static, terrain-focused effects for the broad scope of a campaign and for the more specific details of a particular tactical mission. The

\footnotetext{
${ }^{34}$ Army Doctrine Reference Publication (ADRP) 1-02, Operational Terms and Military Symbols (Washington, DC: Government Printing Office, 2012), 1-28. 2008), 1-5.

${ }^{35}$ Field Manual (FM) 3-0, Operations (Washington, DC: Government Printing Office,

${ }^{36}$ FM 3-0 (2008), 1-5 and 1-9.
} 
Army still is using this framework. ${ }^{37}$ By 2012, Army Design Methodology (ADM) incorporated these variables into a usable synthesis.

Army Design Methodology (ADM)

Army Design Methodology (ADM) is "a methodology for applying critical and creative thinking to understand, visualize, and describe problems and approaches to solve them.” 38 The Army intended ADM as a conceptual planning tool, not as a replacement for MDMP. Rather, ADM helps planners understand an ill-structured problem and develop a conceptual solution. A detailed process like MDMP is still necessary to develop an executable plan. ${ }^{39}$

To understand what the Army meant by ill-structured problems, one must refer to the 2010 FM 5-0, The Operations Process. Ill-structured problems were the kind of problem that relatively few were accustomed to solving. FM 5-0 (2010) introduced "Design” as a method to solve such problems and specifically referenced the OE from Iraq in 2003, where problems different from those of the conventional tactical realm confronted commanders. ${ }^{40}$ For example,

${ }^{37}$ ADRP 5-0 (2012).

${ }^{38}$ ADRP 5-0 (2012), 2-4.

${ }^{39}$ The author acknowledges encouragement of ADM-like concepts in joint and strategiclevel capacities prior to 2012. General (GEN) J.N. Mattis, who was the US Joint Forces Commander in 2008, published his assessment of Effects Based Operations (EBO) through a staff memorandum. GEN Mattis dismissed the concept of EBO because it focused on the effects of targeting and did not account for the human dimension of warfare. Although "Design" did not yet exist, GEN Mattis favored planning methodologies that clearly defined a problem, developed an appropriate conceptual solution, yet enabled subordinate units to plan in detail and execute accordingly.

${ }^{40}$ The need to link tactical action to strategic objectives dates back well before OIF. The Franco-Prussian War from 1870 to 1871 serves as a historical example of this principle. Despite impressive German tactical victories in that war, the French Second Empire collapsed due to the capture of Napoleon III. The collapse left no French government for German Chancellor Otto von Bismark had no negotiate with, and the Prussian system for linking tactical action to strategic and political goals failed. Source: "(Evolution of Operational Art) Lesson 7: Moltke and the Franco 
defeating an enemy army and seizing key cities were relatively routine tasks that units practiced at combat training centers. However, "establishing a safe and secure environment” was not. The latter entailed efforts and thought processes that relatively few had practiced. Design captured lessons learned during the first eight years of OEF and OIF and provided a methodology to help commanders and staffs understand "persistent conflict," the "evolving character of conflict," and to anticipate change. ${ }^{41}$ Between 2010 and 2012, the Army refined Design into the process known in ADRP 5-0 (2012) as ADM.

A set of base activities comprises ADM: frame the operational environment, frame the problem, and develop an operational approach. Reframing is also an essential component. Framing the operational environment entails "defining, analyzing, and synthesizing the characteristics of the operational and mission variables.” The operational variables are the PMESII-PT introduced in 2008. The mission variables are the corresponding METT-TC. Framing has two components: framing the current state and framing the desired future state. Framing the current state includes "identifying and explaining behaviors of relevant actors ... within a social network who (act) to advance personal interests.” An actor ranges from individual people to states or state governments to corporations to terrorist or criminal networks. Framing the future state involves “envisioning desired conditions of an operational environment (a desired end state)." What is also noteworthy is that ADRP 5-0 (2012) specifies, “conditions may be tangible or intangible, military or nonmilitary.” Framing the problem means, “identifying and

Prussian War,” Advanced Military Studies Program, School of Advanced Military Studies, US Army Command and General Staff College, 2014.

${ }^{41}$ Field Manual (FM) 5-0, The Operations Process (Washington, DC: Government Printing Office, 2010), 3-1, 3-2, 3-3, and 3-4. 
understanding those issues that impede progress toward the desired end state.”42 Altogether, framing helps the commander and staff "understand” and "visualize.”

The operational approach is "the broad general [description of] actions to solve the problem.”43 It does not bind a unit to specific tactical actions so much as it identifies a general line of effort and the supporting objectives required to meet the end state. For example, suppose a unit is participating in an overall mission to restore sovereignty of a failing state that a neighboring country has invaded. One line of effort may be to defeat the invasion force. Supporting objectives might include a certain percentage of attrition and destruction or neutralization of key systems. Other lines of effort may be to establish governance and establish civil control with corresponding supporting objectives. The operational approach does not assign tasks to any subordinate units, specify any locations, or dictate how units will meet objectives. It simply, broadly states the things had to happen in order to achieve the desired end state. Thus, the operational approach is essentially a tool to help the commander "describe” what the unit needs to be accomplish and for the staff to develop courses of action.

Finally, reframing is also an essential component. Reframing is “revisiting earlier design hypotheses, conclusions, and decisions," particularly if the commander realizes any of the frames have changed. ${ }^{44}$ ADRP 5-0 (2012) specifically mentions the need to reframe if the desired end state or mission changes, or if the commander realizes that the desired end state is not achievable or the current approach will not achieve it. This is consistent with the notion of planning as a continuous process. It also fosters the Design goal of anticipating change. Finally, it incorporates the commander activity of "assess.”

${ }^{42}$ FM 5-0 (2010), 2-7, 2-8, and 2-9.

${ }^{43}$ FM 5-0 (2010), 2-10.

${ }^{44}$ FM 5-0 (2010), 3-12. 
ADM has proven its worth over time. A 2012 report cited eight incidents across Iraq,

Afghanistan, and the European Command Area of Responsibility in which units benefitted from ADM or ADM-like thinking. In each case, the unit faced an ill-structured problem and leveraged expertise to develop a conceptual approach that differed from conventional methods. Each unit's leadership credited ADM-like thinking with resolving unfamiliar problems. ${ }^{45}$

Table 1: Comparison of FM 101-5 (1997) and ADRP 5-0 (2012) methodologies for understanding conditions.

\begin{tabular}{|c|c|c|}
\hline & \multicolumn{2}{|c|}{ Understanding the Operational Environment (OE) } \\
\hline & $\begin{array}{c}\text { Field Manual (FM) 101-5, } \\
\text { Staff Organizations and Operations (1997) } \\
\end{array}$ & \begin{tabular}{|c} 
Army Doctrine Reference Publication (ADRP) 5-0, \\
The Operations Process (2012) \\
\end{tabular} \\
\hline \multirow[t]{3}{*}{ Commander drove planning process through: } & Battlefield Visualization & Commander Activities \\
\hline & $\begin{array}{l}\text { Understand current state, envision desired state, } \\
\text { visualize sequence of events }\end{array}$ & Understand, Visualize, Describe, Direct, Lead, Assess \\
\hline & Battlefield Framework & \\
\hline Frame environment through: & Battlespace & Operational Environment (OE) \\
\hline Environment defined in terms of: & Enemy-based & "composite of conditions" \\
\hline $\begin{array}{l}\text { Method to understand complexities of ill- } \\
\text { structured problem and develop conceptual plan: }\end{array}$ & (None) & Army Design Methodology (ADM) \\
\hline Concept: & $(\mathrm{N} / \mathrm{A})$ & $\begin{array}{l}\text { Frame current state, Frame desired state, } \\
\text { Frame problem, Develop operational approach, } \\
\text { Reframe as necessary }\end{array}$ \\
\hline Which took place: & $(\mathrm{N} / \mathrm{A})$ & Prior to Military Decision-Making Process (MDMP) \\
\hline Framing tools: & $(\mathrm{N} / \mathrm{A})$ & $\begin{array}{l}\text { Operational Variables (PMESII-PT) and } \\
\text { Mission Variables (METT-TC) }\end{array}$ \\
\hline Method for detailed planning & Military Decision-Making Process (MDMP) & Military Decision-Making Process (MDMP) \\
\hline Analysis of environment through: & Intelligence Preparation of the Battlefield (IPB) & Intelligence Preparation of the Battlefield (IPB) \\
\hline Which took place: & During Mission Analysis, Step 2 of MDMP & During Mission Analysis, Step 2 of MDMP \\
\hline Consideration of tangible variables: & $\begin{array}{l}\text { Thorough discussion: METT-T factors } \\
\text { - Reiterated throughout FM 101-5 } \\
\text { - } 18 \text { pages in FM 34-130 }\end{array}$ & $\begin{array}{l}\text { Equal: Mission Variables (METT-TC) } \\
\text { - Described on page 1-8 } \\
\text { - Reiterated throughout }\end{array}$ \\
\hline Consideration of intangible variables: & $\begin{array}{l}\text { Some discussion: "Analysis of Other } \\
\text { Characteristics of the Battlefield" } \\
\text { - } 3 \text { pages in FM 34-130 } \\
\end{array}$ & $\begin{array}{l}\text { Equal: Operational Variables (PMESII-PT) } \\
\text { - Described on page 1-7 } \\
\text { - Reiterated throughout }\end{array}$ \\
\hline Overall & $\begin{array}{l}\text { Limited understanding of "battlespace." Emphasis on } \\
\text { tangible variables. }\end{array}$ & $\begin{array}{l}\text { Comprehensive understanding of "operational } \\
\text { environment." Inclusive of tangible and intangible } \\
\text { variables. }\end{array}$ \\
\hline
\end{tabular}

${ }^{45}$ Anna Grome, Beth Crandall, Louise Rasmussen (Applied Research Associates); Heather Wolters, Ph.D. (U.S. Army Research Institute), Incorporating Army Design Methodology into Army Operations: Barriers and Recommendations for Facilitating Integration (Fort Leavenworth, Kansas: U.S. Army Research Institute for the Behavioral and Social Sciences, March 2012), B-1 to B-13. 


\section{Section 2:}

\section{Decision Support Template (DST) and Rapid Decisionmaking and Synchronization Process (RDSP): Anticipation, Flexibility, and Timeliness}

As stated in the introduction, the lack of flexibility and timeliness were criticisms of the Military Decision-Making Process (MDMP) between 1997 and 2001. Klein and Paparone both criticized MDMP’s inflexibility. Shoffner stated that MDMP produced one optimal plan to address one particular set of conditions. Shoffner suggested that a staff “focus (on) ... formulating a workable plan that identifies critical decision points.” ${ }^{46}$ The Decision Support Template (DST) existed in 2000, but Shoffner cited a lack of emphasis. FM 101-5 (1997) placed the DST in an appendix. ${ }^{47}$

Shoffner also examined how doctrine addressed making unanticipated decisions in a timely manner. The FM 101-5 (1997) encouraged an abbreviated MDMP under appropriate circumstances but did not explain what to exclude or how to execute. The commander and staff had to "determine how best to modify the MDMP in a time-constrained environment." ${ }^{48}$ This ultimately left abbreviation to the commander's discretion and did not provide a guide for decision-making under time constraints.

The planning process within ADRP 5-0 (2012) provides appropriate templates for flexibility and timely decisions. The DST and accompanying Decision Support Matrix (DSM) facilitate anticipating future decisions. Anticipation enables a flexible plan. Furthermore, the DST and DSM now receive appropriate emphasis. Regarding unanticipated decisions, the RDSP provides a template to guide a staff through decision-making under time constraints.

\footnotetext{
${ }^{46}$ Shoffner, MDMP, 11.

${ }^{47}$ FM 101-5 (1997), H-8.

${ }^{48}$ FM 101-5 (1997), K-1.
} 


\section{The Decision Support Template (DST)}

The DST and accompanying DSM assist the staff in anticipating decisions the commander will have to make. The staff develops them during MDMP. Intelligence Preparation of the Battlefield (IPB) plays a critical role because it describes the physical terrain within the operational environment (OE) and anticipated enemy Courses of Action (COAs). As MDMP progresses the staff uses this data to develop the DST and DSM to provide a graphical depiction of upcoming decisions.

The DST has not changed since 1997. The DST "graphically represents the decision points and projected situations and indicates when, where, and under what conditions a decision is most likely to be required to initiate a specific activity or event." ${ }^{49}$ It consists of four elements. The first, Time Phased Lines (TPL), “are lines used to represent the movement of forces or the flow of an operation over time.” For example, a staff could place TPLs on a map and label them every two hours. This would enable the commander and staff to anticipate and depict the array of forces at certain time intervals. The second, a Named Area of Interest (NAI), "is a geographical area where information that will satisfy a specific information requirement can be collected.” The intelligence section typically develops NAIs during IPB. They may place an NAI over an intersection to determine whether an enemy will go left or right. The staff would then assign either soldiers or possibly an unmanned aerial vehicle to watch the intersection.

The third, a Targeted Area of Interest (TAI), is “the geographical area or point along a mobility corridor where successful interdiction causes the enemy to abandon a particular course of action or requires him to use specialized engineer support to continue.” The staff may place a TAI along a road in order to destroy an enemy convoy at a specific location. The previously described NAI may become a TAI if the commander decides to engage the enemy force at that

${ }^{49}$ Field Manual (FM) 5-0, Army Planning and Orders Production (Washington, DC: Government Printing Office, 2005), G-14. 
location instead of simply confirm its action. Finally, a Decision Point (DP) is “a point in space and time where the commander or staff anticipates making a decision concerning a specific friendly course of action.”50 Using the previous examples, the staff could tie a DP to the NAI. The staff would first confirm enemy action and then the commander would decide whether to execute a TAI along that stretch of road or deploy forces to attack the convoy.

Interestingly, the concept of "triggers" does not appear in ADRP 5-0 (2012). Although it did not define them, FM 101-5 (1997) referenced specific points or action that would automatically initiate (or “trigger”) specific actions. These actions could include commitment of the reserve, execution of a target, or transition to a subsequent phase. Regardless, given the components of the DST, nothing prevents a commander from incorporating "triggers" as desired.

The DSM accompanies the DST. A DSM is “a written record of a war-gamed course of action that describes decision points and associated actions at those decision points." ${ }^{51}$ Simply put, within the DSM, the staff records any DP they identify during MDMP. The DSM lists additional data as well. This data includes the number of the DP in sequence, its location, the criteria to evaluate, the actions to occur, and the units to execute those actions. Finally, the DSM also names the unit responsible for collecting the information required to make a decision (such as who observes an NAI or TAI).

Although the DST has not changed since 1997, it has received greater emphasis. Shoffner noted that FM 101-5 (1997) buried the DST in an appendix and did not give it proper attention. What is equally notable is that FM 101-5 (1997) referenced the DST throughout MDMP, but only

${ }^{50}$ FM 5-0 (2005), G-14 and G-15.

${ }^{51}$ Field Manual (FM) 5-0, The Operations Process (Washington, DC: Government Printing Office, 2011), 5-5. 
used the term "decision support matrix" once. ${ }^{52}$ Furthermore, FM 101-5 (1997) did not explain what a DSM was. By contrast, the 2005 FM 5-0 began to add emphasis by listing "Decision Support Templates” as a key output of Step 4 of MDMP. ${ }^{53}$ The most recent planning publication, ADRP 5-0 (2012), lists “Potential Decision Points” in the same manner that FM 5-0 (2005) listed “Decision Support Templates.”54 FM 5-0 (2005) also emphasized the DSM as a critical planning tool and ADRP 5-0 (2012) even lists the DSM in the same paragraph as the DST. ${ }^{55}$

The emphasis on Commander's Critical Information Requirements (CCIR) is also noteworthy. Both FM 101-5 (1997) and FM 5-0 (2005) defined CCIR in terms of information required for the commander to make a decision. The difference was in the context. FM 101-5 (1997) mentioned CCIR throughout MDMP as a critical item for staff members to recognize as the plan developed. FM 5-0 (2005) added command emphasis to anticipating decisions. It listed “describe” as a critical commander’s task during his commander’s visualization. Like its predecessor, battlefield visualization, commander's visualization drove the entire planning process. Identifying CCIR was a facet of “describe.” Although it is possible that commanders were doing that before 2005, FM 5-0 (2005) was the first doctrinal manual to formalize the process. CCIR remain a facet of “describe” in commander activities within ADRP 5-0 (2012). Furthermore, ADRP 5-0 (2012) goes so far as to reference timely decision-making when describing CCIR. ${ }^{56}$

\footnotetext{
${ }^{52}$ FM 101-5 (1997), G-8.

${ }^{53}$ FM 5-0 (2005), 3-3.

${ }^{54}$ ADRP 5-0 (2012), 2-12.

${ }^{55}$ FM 5-0 (2005), G-14 and ADRP 5-0 (2012), 4-4.

${ }^{56}$ ADRP 5-0 (2012), 1-5.
} 


\section{Rapid Decisionmaking and Synchronization Process (RDSP)}

The 2006 Field Manual-Interim (FMI) 5-0.1, The Operations Process, introduced the RDSP as "a decision making and synchronization technique for commanders and staffs to use during execution [of a plan]." ${ }^{57}$ Whereas MDMP produces an independent base plan, the Army developed the RDSP as a tool to deviate rapidly from an existing base plan. RDSP can be useful as a response to an unanticipated decision, especially when conditions fundamentally change. Furthermore, whereas MDMP seeks an optimal solution, RDSP simply seeks an acceptable solution. ${ }^{58}$ The RDSP consists of five steps. The first is to compare the current situation to the order. The second is to determine whether a decision and what type, is required. The third is to develop a response. The fourth is to refine and validate the COA. The fifth step is implementation.

During the first step, leaders and staff members identify “exceptional information” as the mission develops. Doctrine defines “exceptional information” as any variance in anticipated conditions that potentially requires an adjustment from the base plan. ${ }^{59}$ In situations where RDSP is suitable, the DSM would not have accounted for the variance and leaders must move to step two. During the second step, leaders further compare the existing situation to the expected situation and confirm how significant the variance is. If the variance warrants a change in plans, then the leaders notify the decision authority and determine how much of the staff needs to be involved in developing a response. What is notable is that the first two steps are reversible or can be concurrent as necessary. During the third step, leaders and staff develop COAs within the

${ }^{57}$ Field Manual-Interim (FMI) 5-0.1, The Operations Process (Washington, DC: Government Printing Office, 2006), 4-5.

${ }^{58}$ FMI 5-0.1 (2006), 4-5.

${ }^{59}$ FMI 5-0.1 (2006), 4-6. 
existing commander's intent and propose any changes to CCIR they deem necessary. They then present their recommendations to the commander. During the fourth step, the current operations cell reviews the selected COA for feasibility, acceptability, and suitability. If the cell deems the COA unacceptable, the staff informs the commander and makes adjustments. If the cell deems the COA acceptable, it progresses into implementation (the fifth step). ${ }^{60}$

It is worthy to note that ADRP 5-0 (2012) acknowledges that leaders' experience and intuition have key roles in RDSP. However, this is not the same as the 1997 abbreviated MDMP that was essentially at the commander's discretion. The RDSP emphasizes incorporation of the experience and intuition of as many people as the circumstances permit before taking a proposal to the decision authority. Thus, the Army has created a doctrinal guide to rapid decision-making. Unfortunately, it is difficult to judge the effectiveness of RDSP. There are no documented cases of units using RDSP in the Ike Skelton Combined Arms Research Library, the Mission Command Training Program (MCTP), or the Center for Army Lessons Learned.

\section{Section 3:}

\section{Alternate Decision-Making Models and their Integration into Doctrine}

Each Military Decision-Making Process (MDMP) critic named in the introduction recommended an alternative decision-making model. Shoffner and Paparone emphasized the need for a more comprehensive understanding of an environment. Klein and Shoffner also advocated intuitive models, such as Recognition-Primed Decision-Making (RPD), and had supporters. They alleged that intuitive models facilitated greater flexibility and timely decisions.

An examination of one theory and five different models yields insight into a broad array of alternatives to the 1997 planning process. Complexity theory, naturalistic decision-making, and emergent strategy contribute to understanding an environment and planning accordingly. Rational

${ }^{60}$ FMI 5-0.1 (2006), 4-5 - 4-10. 
Choice provides a framework to optimize a base plan. Recognition Primed Decision-Making facilitates faster decisions. Finally, Decision Point Tactics helps with anticipating decisions. There is evidence of the theory and each model in current doctrine.

\section{Complexity Theory}

Although complexity theory is not a decision-making model, it informs ones understanding of an environment and shapes decisions. It is evident in Army Design Methodology (ADM). Complexity theory regards the results of human interaction, which, collectively, produce a system. Columbia professor Robert Jervis defined a system as “(a) a set of units or elements is interconnected so that changes in some elements or their relations produce changes in other parts of the system, and (b) the entire system exhibits properties and behaviors that are different from those of the parts.”61 Author Neil Harrison’s discussion of complexity compliments Jervis’s definition saying, “in complexity, a system is more than merely the aggregation of its parts: the system is modeled as emerging from the relationships and interactions between member agents." ${ }^{2}$ Thus, a system consists of the interactions between the agents within it and the actions that result are interdependent.

ADM accounts for such phenomena. ADRP 5-0 (2012) states, “understanding of the situation ... includes identifying and explaining the behaviors of relevant actors ... within a social network." ADM also encourages analysis of the interactions of those actors, "clarifying the relationships among actors requires intense effort since these relationships must be examined

${ }^{61}$ Robert Jervis, System Effects: Complexity in Political and Social Life (Cambridge: Cambridge Univ Press, 1997), 6.

${ }^{62}$ Neil Harrison, Complexity in World Politics: Concepts and Methods of a New Paradigm (Albany: State University of New York Press, 2006), 33. 
from multiple perspectives.” ${ }^{63}$ Therefore, ADM facilitates identifying not only the actors within a system, but clarifying the relationships between them and the significance of those relationships. Although complexity theory is not a decision-making model by itself, it does facilitate a more comprehensive understanding of conditions within an operational environment (OE). This understanding contributes to improved decision-making, regardless of whether one makes the decision through detailed analysis and comparison of options, through anticipation of an outcome, or through their own intuition.

\section{Naturalistic Decision-Making}

Naturalistic decision-making considers how individuals make decisions in a natural environment (such as an OE) as opposed to any environment where conditions are preset or artificial (such as a combat training center). Under naturalistic decision-making, a decision maker considers any combination of ten variables. These include time constraints; high stakes; their own experience; missing, ambiguous, or erroneous information; ill-defined goals; poorly defined procedures; cue learning (based on perceived patterns); larger context of a given situation; dynamic (changing) conditions, and decisions made by teams. ${ }^{64}$

ADM leverages several of these variables. The most prevalent examples come through framing and reframing. ADRP 5-0 (2012) states that "framing ... help[s] individuals understand situations and respond to events ... (through) a group ... (that) considers the perspective and world views of others to understand the situation fully.” First, the sheer requirement for situational understanding suggests some information will be missing, ambiguous, or erroneous. Before a group can develop a plan of action, it requires situational understanding. If the

${ }^{63}$ ADRP 5-0 (2012), 2-7.

${ }^{64}$ Gary Klein, PhD, Sources of Power: How People Make Decisions (MIT: First MIT Press, 1999), 6. 
understanding is incomplete, there will initially be ill-defined goals. Next, ADRP 5-0 (2012) specifically mentions the "group" that executes ADM to develop the understanding and response, which encompasses decisions made by teams.

The full understanding through the perspectives and worldviews of others includes the larger context. In fact, ADRP 5-0 (2012) uses the word “context” throughout the ADM section. However, ADM does not encourage planning based on understanding at any one time because it acknowledges that the environment changes. Rather, reframing refers to "continuous assessment ... revisiting earlier hypothesis, conclusions, and decisions ... (that) can lead ... (to) an entirely new plan." 65 This is adapting to changing conditions. It is also reasonable to deduce that changes in patterns identified in the environment, or cue learning, could result in a reframe.

\section{Emergent Strategy}

Emergent strategy accounts for unintended patterns. In 1994, Henry Mintzberg defined strategy as both a plan and a pattern. As a plan, strategy served as a course of action. As a pattern, strategy was also a "consistency in behavior over time.” ${ }^{66}$ Mintzberg further broke this down into the "intended" strategy (what one wanted to achieve) and the "realized" strategy (the actual outcome). A “deliberate” strategy was one in which intentions were fully "realized.” An “unrealized” strategy was one in which intentions were not “realized.”

Mintzberg also accounted for an “emergent” strategy, “where a realized pattern was not expressly intended.” ${ }^{67}$ If an entity adopted the “emergent” strategy, Mintzberg considered this an "umbrella" strategy, where "the broad outlines are deliberate while the details are allowed to

\section{${ }^{65}$ ADRP 5-0, 2-5 and 2-6.}

${ }^{66}$ Henry Mintzberg, The Rise and Fall of Strategic Planning: Reconceiving Roles for Planning, Plans, Planners (New York: The Free Press, 1994), 23.

${ }^{67}$ Mintzberg, The Rise and Fall, 25. 
emerge within them.” ${ }^{68}$ Mintzberg further stated that one must assess the "realized” strategy to determine whether it was "deliberate” or "emergent."

Army planning doctrine incorporates emergent characteristics through the combination of the MDMP and reframing from ADM. The result of MDMP is an optimized plan, selected based on analysis and comparison to other options. Such a plan is consistent with an "intended" strategy. If $\mathrm{OE}$ conditions do not develop as anticipated, a unit is required to take different action to address those conditions. This is an example where a unit executes an "emergent” strategy as the result of an "unrealized” strategy. Now suppose the unit re-assessed, understood that the “emergent” strategy was actually more practical under their conditions, and adopted it. This would be an example of a reframe according to ADRP 5-0 (2012). Remember, reframing is “continuous assessment ... revisiting earlier hypothesis, conclusions, and decisions ... (that) can lead ... (to) an entirely new plan.”69

Consider the counterinsurgency (COIN) strategy during Operation Iraqi Freedom (OIF) as an example. In preparation for OIF, the “intended” strategy was to fight a conventional opponent. During OIF, an unanticipated insurgency rose and used guerilla-style tactics. Units adjusted their tactics in response to the ground conditions; they adopted an "emergent” strategy. Planners reframed the environment to accommodate the actual situation and developed a commensurate approach.

The Rapid Decisionmaking and Synchronization Process (RDSP) also has characteristics of emergent strategy. A leader initiates RDSP when one identifies a variance from originally anticipated conditions, which forces a new course of action to address. Thus, an expedited form

${ }^{68}$ Mintzberg, The Rise and Fall, 25.

${ }^{69}$ ADRP 5-0 (2012), 2-6. 
of reframing takes place and the new conditions result in a new plan. This is parallel to the process described above, albeit not as detailed or deliberate.

\section{Rational Choice}

Stanford University Professor James March presented the rational choice model, where the decision maker considers four questions. The first concerns the alternatives available under the circumstances. The second concerns the consequences of each alternative and how likely the consequences are to happen. The third concerns the decision maker's preferences. Finally, the fourth concerns how one actually makes the choice. ${ }^{70}$ The MDMP aligns with this model. In Steps 1 and 2, Receipt of Mission and Mission Analysis, the commander gains understanding of their circumstances. In Step 3, Course of Action (COA) Development, the commander considers multiple options. In Step 4, COA Analysis, the commander considers the consequences of selected options. In Step 5, COA Comparison, the commander's compares each COA according to preferences (also known as evaluation criteria). In Step 6, COA Approval, the commander chooses a COA based on preferences and requirements. ${ }^{71}$

This model has implicit benefits and limits. The benefits are that it is thorough and detailed. ADRP 5-0 (2012) states, "the MDMP helps leaders apply thoroughness, clarity, sound judgment, logic, and professional knowledge to understand situations, develop options to solve problems, and reach decisions." ${ }^{72}$ However, the limits are that it can be cumbersome and time consuming.

${ }^{70}$ James March, A Primer on Decision Making: How Decisions Happen (New York: The Free Press, 1994), 3-4.

${ }^{71}$ ADRP 5-0, 2-12.

72 ADRP 5-0, 2-11. 


\section{Recognition Primed Decision-Making (RPD)}

Gary Klein, a renowned research scientist, introduced the Recognition Primed DecisionMaking model in $1985 .^{73}$ This model facilitates rapid decision-making by leveraging experience and knowledge. The decision maker individually assesses a situation and then determines which COA is appropriate for it without detailed analysis or comparison of multiple COAs. The decision maker might review multiple COAs in his own mind before settling on the best one. Unlike the Rational Choice model, RPD does not require comparison of COAs. Neither does it call for an optimal solution, but rather simply a workable solution. Therefore, while this model facilitates rapid decision-making, it is not suitable for ill-structured problems or a situation that requires detailed analysis. Nonetheless, its characteristics are evident in planning doctrine.

Battle drills at the tactical level are an example of RPD. Doctrine intended battle drills for situations that develop too fast to allow for detailed analysis and deliberate planning. Forced to decide quickly, the ground leader would likely make an intuitive decision based on existing knowledge and precedents.

Regarding commanders and staffs, Lieutenant Colonel (LTC) Gregory Banner proposed an alternate model for rapid decision-making at the tactical level. In his 1997 model, planners identify and compare the critical components of one Course of Action (COA) in order to determine optimal execution. This was in lieu of comparing multiple COAs. For example, if a unit knows it must cross a river, attack, and defend, it would compare different ways of executing each of those components under their given circumstances. This would include where to cross the river, what direction to attack from, and how best to defend the newly seized objective. The unit

\footnotetext{
${ }^{73}$ Klein Associates, Inc., Making Decisions, 7.
} 
would not examine alternate ways to achieve the same result, such as an air assault. This saves time because planners can focus on options within a single overall COA. ${ }^{74}$

Banner’s model resembles a hybrid of Rational Choice and Recognition Primed Decision-Making (RPD). Although the model only considers one COA, it still requires a commander to choose the single COA before the staff commences planning. In such a case the commander would likely leverage experience and existing knowledge to make an intuitive decision. Then, a staff would still list available options within the COA, compare them, and decide which options are best. This it is comparable to a directed COA.

Finally, the Rapid Decisionmaking and Synchronization Process (RDSP) includes elements of RPD. The intent of RDSP is a tool to facilitate timely decision-making by eliminating the need for a thorough analysis or all seven steps of MDMP. ADRP 5-0 (2012) states, "the RDSP lets leaders avoid the time-consuming requirements of developing decision criteria and comparing (COA’s) ... leaders combine their experience and intuition to quickly reach situational understanding. Based on this, they develop and refine workable COAs."75 Furthermore, the RDSP focuses on developing a single, workable COA to address changed conditions in the OE. The challenge is to know when detailed analysis is required and when an intuitive decision is appropriate. Such a decision is ultimately at a leader's discretion, based on the particular situation and time available.

\section{Decision Point Tactics}

The Opposing Forces (OPFOR) at the National Training Center in Fort Irwin, California developed Decision Point Tactics as a way to fight Army maneuver units conducting force-on-

${ }^{74}$ LTC Gregory T. Banner, “Decision Making - A Better Way,” Military Review (September-October 1997), 53.

${ }^{75}$ ADRP 5-0 (2012), 4-6. 
force training exercises. In a 1997 article, LTC Peter Palmer described them as "the art and science of employing available means at a specific point in space and/or time where the commander anticipates making a decision concerning a specific friendly course of action (COA). This decision is directly associated with threat force activity (action/reaction) and/or the battlefield environment." ${ }^{76}$ Essentially, the OPFOR developed and analyzed multiple COAs during planning, but did not select one to execute until contact (or imminent contact) with the maneuver unit in training. This concept gave the OPFOR commander flexibility, as he had multiple options to employ based on what the maneuver unit was doing. As a result, execution required anticipation of different possibilities and thorough reconnaissance to determine the maneuver unit's COA.

Decision Point Tactics shared many characteristics with the DST and DSM. Contingency is the basis for both, which requires a commander to anticipate a future decision. Similarly, both require information collection through reconnaissance in order to confirm or deny potential conditions or adversary actions. Although Decision Point Tactics were never official Army doctrine, Palmer used doctrine to develop them. His 1997 article went into great depth about processes such as IPB and MDMP. Also noteworthy, he made extensive use of DPs and CCIRs.

\section{Section 4:}

\section{Current Integration and Education}

\section{Current Integration}

Observers at the Mission Command Training Program (MCTP) at Fort Leavenworth, Kansas revealed recent trends observed regarding execution of the planning process during division-level Warfighter Exercises (WFX) at Fort Leavenworth. A WFX is a computer simulation that prepares units to operate within complex scenarios. They are tools by which the

${ }^{76}$ LTC Peter J. Palmer, "Decision Point Tactics and the Meeting Battle: Fighting the Enemy, Not the Plan,” Infantry (January-February 1997), 29. 
Army evaluates command and staff readiness to perform doctrinal missions. Two key issues observed involved Army Design Methodology (ADM) and Commander’s Critical Information Requirements (CCIR). ${ }^{77}$

Few units, if any, exercised ADM during their WFX. Observers stated the most likely reason was time constraints. The units were under pressure to develop plans to address the problems in the simulation and did not devote time to detailed analysis. In fact, observers stated that under time constraints, units often abbreviated Mission Analysis and sometimes did not conduct it at all. It is understandable that these same units would not conduct ADM. ADM encompasses more abstract variables than Mission Analysis. This requires more time and expertise to analyze. Observers cited little evidence that units had rehearsed or otherwise conducted ADM prior to the WFX. If a unit is not familiar with ADM, they will likely not conduct it when time constrained. ${ }^{78}$

This behavior serves as an example of Peter Drucker's management by objectives. In Drucker's theory, management and employees agree on specific objectives that support an overall goal. Management evaluates employee performance based on achievement of objectives. ${ }^{79}$ This gives employees incentive to focus solely on those objectives, even if that is not the intent. In the case of WFX units, it appears that staff members would focus on developing a COA more so than understanding the environment. Behavior like this is understandable since the unit was under a time constraint to produce a plan. In a WFX, the agreement between the commander and staff members to abbreviate Mission Analysis was likely tacit, but present nonetheless. Even without

${ }^{77}$ LTC Matthew Morgan and Dennis Rasdall (LTC, Ret), interviewed by author, Fort Leavenworth, Kansas, June 11, 2014.

${ }^{78}$ Morgan and Rasdall interview.

${ }^{79}$ Peter F. Drucker, The Practice of Management (New York: Harper and Row, Publishers, Inc., 1986), 121-136. 
the commander directing so, the staff would avoid something abstract and difficult (ADM or Mission Analysis) and move directly into the deliverable (the plan). Having received the deliverable, the commander was content.

The danger is the potential for the staff to fail to identify facts about the environment or consequences of specific interactions that could shape the plan. In rushing to COA Development, the staff could inadvertently disregard a variable that was critical to an environment. It is difficult to fault the commander or staff for focusing on a deliverable when under a time constraint. However, those actions can set a dangerous precedent as a unit moves into real world missions. Fortunately, MCTP observers noted that units usually understood the importance of analysis by the end of the WFX.

The second issue involved CCIR. Observers stated that units seemed to misunderstand CCIRs and typically did not tie them to actual decisions. Units normally tasked the intelligence section with developing CCIRs. The intelligence section would often identify valid information requirements (IR). However, it rarely tied them to a commander's future decision. These IRs only filled missing or ambiguous information. ${ }^{80}$ As a result, these IRs would help refine a plan, but did not qualify as CCIRs. According to ADRP 5-0 (2012), CCIRs are, “information requirement[s] identified by the commander as being critical to facilitating timely decisionmaking.” ${ }^{81}$ By not tying CCIR's directly to anticipated decisions, the staff inadvertently misdirected both the commander's attention and the collection assets to lower priority issues.

Observers attributed this to units' experience in counterinsurgency (COIN) operations during Operation Enduring Freedom (OEF) and Operation Iraqi Freedom (OIF). Throughout the course of OEF and OIF, a unit normally inherited a situation in which it could maintain initiative

${ }^{80}$ Morgan and Rasdall interview.

${ }^{81}$ ADRP 5-0 (2012), 1-5. 
through steady-state operations. This often required continuous information collection, but left the commander with few actual decisions to make. As more units experienced rotations in which IR collection sufficed for steady-state operations, those practices became the norm. In fact, it appears that WFX staff members believed that there was no difference between IRs and CCIRs.

This kind of behavior is similar to what University of Pennsylvania Professor Jamshid Gharajedaghi would classify as defining a problem according to an existing solution. In Gharajedaghi's theory, training exposes professionals to cases that resemble the actual problems they will encounter in real life. As a result, professionals learn solutions that they believe are applicable, so long as these professionals can relate the real problem to the training case. Once one identifies a similarity, all they need to do is apply the learned solution. ${ }^{82}$

Although the use of IRs is more of a habit than a "solution,” units' misuse of CCIRs reflects this principle. As staff members learned how to develop IRs in steady-state operations, they accepted the practice as a norm that was applicable in any situation that required information collection. This paradigm became problematic when staff members faced a situation where collected information actually drove the commander's decision.

To their credit, units usually demonstrated proper procedure after clarification and more repetitions. During a WFX, observers would explain the function of analysis and CCIRs and provide example techniques. Units were often receptive and considered techniques that were suitable to them. The same observers who worked with units during a WFX would often later observe them forward deployed. During deployments, observers noted that many units had integrated the analysis and CCIR techniques that they found suitable. ${ }^{83}$ Therefore, it seemed that unit members’ problem was a lack of exposure and practical application of the doctrinal

82 Jamshid Gharajedaghi, Systems Thinking: Managing Chaos and Complexity: A Platform for Designing Business Architecture (Burlington: Elsevier, 2006), 126-127.

${ }^{83}$ Morgan and Rasdall interview. 
processes. Once units understood the methods and their purposes, they would become proficient at them with more repetition. In fact, another observer noted that one unit had discretely integrated the ADM into its Standard Operating Procedures (SOP) during the last calendar year. Two more units were practicing it even though it was not yet unit SOP. ${ }^{84}$

\section{Education}

This investigation also considered the academic curriculum at the Command and General Staff Officer Course (CGSOC). The CGSOC curriculum is a field grade officer's first exposure to the planning process in a professional military education environment. The curriculum includes ADM, MDMP, and RDSP but seems disproportional. Furthermore, it is difficult to measure the curriculum's effectiveness. Students' experience with the planning process varies, but the most recent classes demonstrate a great eagerness to learn.

The CGSOC curriculum includes instruction and practical application of the planning process. First, CGSOC students participate in thirty-four hours of MDMP during a planning exercise that involves a Joint Task Force. ${ }^{85}$ Next, students participate in a brigade-level exercise that consists of eight hours of ADM, twenty-four hours of MDMP, and twenty-two hours of RDSP. ${ }^{86}$ Finally, students participate in a division-level planning exercise that includes thirty-four 2014.

${ }^{84}$ LTC Richard Dembowski, interviewed by author, Fort Leavenworth, Kansas, July 29,

85 "C400 Army Doctrine and Planning.” Command and General Staff Officer Course (CGSOC) Common Core, US Army Command and General Staff College, 2014.

${ }^{86}$ Albert Stahl, "Lesson Plan for Lesson O319: ADM for Cerasia.” O300 Decisive Action: Brigade Operations, Command and General Staff Officer Course (CGSOC) Advanced Operations Course (AOC), US Army Command and General Staff College, 2014; David Goebel, "Lesson Plan for Lesson O320: Planning for Brigade Operations.” O300 Decisive Action:

Brigade Operations, Command and General Staff Officer Course (CGSOC) Advanced Operations Course (AOC), US Army Command and General Staff College, 2014; Frank James, "Lesson Plan for Lesson O399: Executing Brigade Operations.” O300 Decisive Action: Brigade Operations, Command and General Staff Officer Course (CGSOC) Advanced Operations Course (AOC), US 
hours of MDMP. ${ }^{87}$ Simple math reveals that MDMP accounts for seventy-five percent of the planning curriculum. Regarding evaluation, instructors evaluate students understanding through individual requirements and participation in practical application during each module. Individual requirements include written examinations graded according to a rubric. Participation in practical application, also graded according to a rubric, includes the quality of the team's finished products as well as the individual's contribution.

It is difficult to assess the effectiveness of the CGSOC curriculum regarding the planning process. The written examination only dates back to 2012 and includes other facets of tactics in addition to the planning process. It is difficult to isolate data specific to the planning process. ${ }^{88}$ An instructor arbitrarily assesses an individual's contribution to practical application. The overall quality of the finished group product influences the individual grade. This creates a loophole for an individual to contribute less than other team members yet still receive a passing grade.

Department of Tactics (DTAC) instructors have observed a change in student dynamics at CGSOC. Dr. Frank James (LTC, Retired) and Albert Stahl (LTC, Retired) have both been CGSOC DTAC instructors since 2008 and have taught a combined fourteen staff groups. They observed differences in students’ experience with planning between their respective arrivals at CGSOC and the most recent staff groups.

James and Stahl each stated that from their arrival until approximately 2012, students’ understanding of and experience with the planning process varied. Their reception of it in an

Army Command and General Staff College, 2014.

87 "O200 Decisive Action: Division Operations." Command and General Staff Officer Course (CGSOC) Advanced Operations Course (AOC), US Army Command and General Staff College, 2014.

${ }^{88}$ The author of this paper also attempted to examine how CGSOC students perform on the School of Advanced Military Studies (SAMS) entrance exam. However, the SAMS staff confirmed that their entrance exam does not necessarily measure the outputs of CGSOC and changes from year-to-year. 
academic environment varied as well. Both James and Stahl stated that a higher proportion of students during that period had multiple combat tours to OEF and OIF. During these tours, students often worked in capacities where they were responsible for certain facets of the planning process. However, relatively few understood the entire planning process.

For example, Stahl cited one student who was extremely proficient at targeting, but had little exposure to much else. That particular student was convinced that targeting, alone, sufficed for planning. This technique may have been valid during a particular period and at a particular location. In COIN operations, it is common for a unit to inherit a relatively developed sector where little detailed planning is necessary. In such a case, the routine practice of targeting could enable a unit to achieve its desired effects and make other facets seem irrelevant. However, that is not always the case. This is another example of defining a problem according to an existing solution.

By contrast, some students had served in positions where they participated in or even led the entire planning process. Students shared valuable experience with classmates and instructors alike. On the downside, these students brought habits developed under specific conditions that may or may not be applicable to all environments. Overall, some students seemed very receptive to the planning process. Others only seemed to regard the facets they believed would be applicable in subsequent assignments, many of them another combat tour. ${ }^{89}$

However, recent staff groups demonstrated a different mindset. James noted that the most recent staff groups consisted of a higher overall caliber of students who did not have any preconceived notions about the planning process. He attributed this to a centralized selection process and students’ lack of experience. Beginning in approximately 2014, the Army only selected fifty percent of Majors to attend CGSOC at Fort Leavenworth. The Army based selection

${ }^{89}$ Frank James, PhD, interviewed by author on August 14, 2014 and Albert Stahl on August 12, 2014. 
on performance in previous assignments and demonstrated potential for increased responsibility. This was in contrast to previous years, where all Majors attended regardless of past performance or potential. Furthermore, very few of the students cited experience with the entire planning process, and even fewer had ever led it. The most recent staff groups took a greater overall interest in the entire planning process compared to their predecessors, although both demonstrated understanding of it. ${ }^{90}$

\section{Section 5:}

\section{Conclusions and Recommendations}

\section{Conclusions}

Evaluation using the modified version Shoffner's 2000 criteria shows mixed results. The current doctrinal planning process provides a framework for a more comprehensive understanding of conditions, emphasizes anticipation of change, and outlines a technique to make decisions faster. However, units seem to misunderstand and consequently misuse the planning process. The examination on teaching and learning the planning process is inconclusive.

The planning process in ADRP 5-0 (2012) adequately incorporates the complexities of the operational environment (OE). In 2000, Shoffner noted the anticipated complexities and ambiguity of twenty-first century environments. Similarly, in 2001 Paparone recommended that future doctrine devote more attention to multidimensional aspects of planning. The 2007 adoption of the term "operational environment” to replace "battlefield” emphasizes the composite of conditions a unit can encounter. The corresponding “operational variables” (PMESII-PT) provide a framework to foster consideration of the impact of intangible variables on the operational environment. Army Design Methodology (ADM) incorporates complexity theory and naturalistic decision-making into a planning tool. This provides a framework for commanders and staffs to

\footnotetext{
90 James and Stahl interviews.
} 
translate the composite of environmental conditions into a useful analysis. If used as intended, this analysis can provide a comprehensive understanding of the complexities of the OE.

The current planning process accounts for the changing nature of the OE. Klein, Shoffner, and Paparone each criticized the Military Decision-Making Process (MDMP) as inflexible. Planning doctrine has addressed those criticisms by providing frameworks for flexibility. First, ADM incorporates Minztberg's emergent theory with the concept of reframing. This provides a framework to adapt an operational approach to environmental conditions as they change. This supports the Army Doctrine Publication (ADP) 3-0, Operations (2011), definition of adaptability, “Army leaders accept that no prefabricated solutions to tactical or operational problems exist. Army leaders must adapt their thinking, their formations, and their employment techniques to the specific situation they face." 91

Second, the Decision Support Template (DST), Decision Support Matrix (DSM), and Commander's Critical Information Requirements (CCIR) foster anticipating future decisions. Such anticipation shows that doctrine acknowledges that there are factors that can influence execution of a plan. Doctrine provides the DST and DSM as tools to help evaluate the impact of such factors. The commander and staff also clarify what to do if an anticipated condition develops. This is often a deviation from the base plan and the DSM provides an option to address an emergent factor. CCIR completes the DSM by asking the specific questions the commander needs answered in order to make decisions. This supports the ADP 3-0 (2011) definition of flexibility, "the capability to act quickly across the range of military options.” Although the DST, DSM, and CCIR were not new tools in 1997, doctrine did not emphasize them. Current doctrine emphasizes them as outputs of MDMP.

${ }^{91}$ ADP 3-0 (2011), 7 and 8. 
The current process outlines a technique for timely decisions. Klein, Shoffner, and Paparone each criticized MDMP as cumbersome and slow. Although doctrine still allows for deliberate planning through ADM and MDMP, it also accounts for situations that may require faster decisions. First, the emphasis on anticipating future decisions through the DSM helps to enable faster choices. The staff can recognize the potential for a decision under specific circumstances and be prepared to execute. Second, for unanticipated decisions, the Rapid Decisionmaking and Synchronization Process (RDSP) incorporates Klein’s Recognition Primed Decision-Making to leverage experience and intuition. This allows for a relatively faster decision by eliminating the need for detailed analysis and deliberate comparison of options. The challenge is to know when an intuitive decision is appropriate versus when a situation requires detailed analysis. This is ultimately at a leader's discretion and no formula or doctrinal framework can tell an individual how to make such a decision. Nonetheless, doctrine provides frameworks for faster decisions through the DSM and RDSP. This supports this author's definition of timeliness as providing adequate time for subordinate units, two levels down, to react to a decision, plan for its implementation, and execute it in the face of a thinking, proactive adversary.

The planning process is applicable at the operational and tactical levels. Units at both levels can leverage the process to understand conditions and develop conceptual and detailed plans commensurate to their needs. ADM provides a framework to understand an environment through complexity theory and naturalistic decision-making. MDMP incorporates Rational Choice to optimize the best option according to given conditions. MDMP also allows a commander to limit the options for a staff to consider. This resembles Banner's hybrid of Klein's RPD and Rational Choice. Therefore, units at the operational and tactical levels can use the planning process as they find it suitable.

The results of the examination into teaching and learning the planning process are mixed. Mission Command Training Program (MCTP) observations indicate that units focus on 
deliverables (i.e., a plan) in lieu of detailed analysis and anticipation that can shape the plan. Staff members also misunderstand the doctrinal tools that can provide clarity on the environment and its potential effects. It is understandable that a unit would focus on a deliverable, but doing so entails significant risk. In addition, staff members appear susceptible to a bias toward existing solutions without regard to fully understanding their current conditions. However, observations also indicate that units are willing to learn and incorporate doctrine and develop techniques that they find suitable.

The Command and General Staff Officers Course (CGSOC) curriculum appears to provide comprehensive instruction on the planning process. However, MDMP comprises an overwhelming proportion of the curriculum. Furthermore, a lack of access to empirical data makes it difficult to measure the curriculum's effectiveness. Like Warfighter Exercise (WFX) participants, some CGSOC students demonstrate a bias toward existing solutions without regard to current conditions. Also like WFX participants, recent CGSOC classes demonstrate a desire to learn the planning process.

Overall, this investigation concludes that the current planning process allows for more flexible plans and more timely decisions than it did in 1997. It achieves this is by providing a framework for a more comprehensive understanding of conditions, emphasizing anticipation of change, and outlining a technique to make decisions faster. However, the doctrinal tools, alone, are not sufficient to solve the problems that units will encounter. The commander and staff must understand and use the tools in order to achieve the intended results. The problem seems to be twofold. First, units are quick to rush to developing an executable plan because that is the measurable. Second, units misunderstand the frameworks and apply preconceived notions as solutions. 


\section{Recommendations}

There are four recommendations to enhance use of the planning process that result from this study. These include: creating incentive for analysis and anticipation during planning, improving unit internal education of the planning process, emphasizing continued iteration of the planning process, and areas of future study. Collectively, these could foster thinking beyond tangible products and leverage existing opportunities to enhance units' use of the planning process.

First, units need incentive to perform analysis and anticipate future decisions. Understanding the benefit of analysis and anticipation could suffice. It seems that current units are prone to moving straight into COA Development because it produces a tangible product, directly related to solving the problem. Units seem to view analysis and anticipation as cumbersome and meticulous. Although there is probably truth to that, performing analysis and anticipation up front saves time long-term. Analysis yields a more comprehensive understanding of conditions, which results in a more thorough plan. A more thorough plan alleviates unanticipated decisions.

Field grade officers must convince the commander of the benefits of analysis and anticipation if he does not already subscribe to that philosophy. Persuasion could come through a formal brief, but the informal "collaboration and dialogue” that ADRP 5-0 (2012) describes could also prove effective. The venue would be the one through which the field grades could best persuade the commander. Regardless, according to the trends that James and Stahl noted, CGSOC students take the planning process seriously. This attitude could prove valuable as students move into units where commanders may not be familiar with current doctrine. It is incumbent on field grade officers to convince the commander of the value of analysis and anticipation, incorporate appropriate techniques into unit SOPs, and enforce them accordingly. 
Second, units could develop internal education programs regarding the planning process. Education could come through various forms. One is to develop a series of professional development courses in units. During these courses, a CGSOC or SAMS graduate could give instruction on the planning process as it pertains to upcoming exercises or missions. Practical application could accompany the instruction. It could be in the form of a planning exercise or even watching film to identify and assess the elements of ADM and other forms of decisionmaking. The SAMS curriculum uses the movies Argo and Moneyball to demonstrate the principles of ADM. Units could use these or others such as Lawrence of Arabia or Charlie Wilson's War to do the same. It would be a matter of allotting the time and appointing the appropriate instructor for units to develop such a program. A commander could also assign a reading list to discuss during designated times as well.

Third, continued iterations of the planning process would refine planning skills once a unit teaches them. The WFX is the most obvious way to practice planning and receive objective feedback, but there are venues to practice as well. Opportunities to apply ADM will likely present themselves. Remember, the Army created ADM as a tool to address ill-structured problems problems that few are accustomed to solving. Ill-structured problems are not limited to the world stage. As the Army drawdown commences, units must determine how to achieve effects with fewer resources. Relatively few in the Army are familiar with these conditions. This presents an opportunity for units to examine ways to train on everything from the most basic soldiering skills to collective tasks. Units will likely have to combine tools like simulations with actual exercises. This is likely contrary to what soldiers have come to expect. Convincing soldiers of the validity of new methods can be an ADM task by itself, essentially developing an internal information campaign. In addition, units may have to restructure to achieve the maximum effects. Determining the best task organization may force units to use unorthodox structures and techniques. 
The principles of understanding an environment, developing and comparing options, and optimizing the best option remain the same regardless of the event. There are built-in opportunities for units to perform iterations of planning and expand understanding of the principles. If units leverage opportunities to demonstrate the principles, staff members will be more familiar with the methodologies and be more proficient at them during actual missions.

Finally, the author recommends future studies on the effectiveness of the CGSOC curriculum. This is because it was difficult to isolate information pertaining to how students learn the planning process. For one study, CGSOC could isolate the data pertaining to the planning process on the Department of Tactics (DTAC) exam and compare results to other facets of the exam. This could tell how students are receiving the planning process curriculum compared to other facets of tactics.

Another method could be to administer a diagnostic exam early in the curriculum. After the curriculum is complete, CGSOC could compare the results of the diagnostic exam to the DTAC exam. If students scored higher on the post-curriculum exam than the diagnostic, that could indicate the curriculum is adequate. Another method may be to test for a correlation between performance on the CGSOC planning curriculum and success as an operations or executive officer. Such a study would have to account for variables outside of CGSOC that could contribute to success in such duty positions, like prior experience. It would also have to isolate performance in facets of the positions pertaining to planning. For example, it would not be valid to measure one’s performance in maintenance-related issues to the CGSOC planning curriculum. However, a study that compares CGSOC performance to duty performance could reveal trends and serve as a basis for other studies. 


\section{Appendix 1}

\section{CONSENT AND USE AGREEMENT FOR STRUCTURED INTERVIEW MATERIALS}

You have the right to choose whether or not you will participate in this structured interview, and once you begin you may cease participating at any time without penalty. The anticipated risk to you in participating is negligible and no direct personal benefit has been offered for your participation. If you have questions about this research study, please contact the student at: david.m.ike.mil@mail.mil or Dr. Robert F. Baumann, Director of Graduate Degree Programs, at (913) 684-2742.

To: Director, Graduate Degree Programs

Room 3517, Lewis \& Clark Center

U.S. Army Command and General Staff College

1. I, participated in a structured interview conducted by

MAJ David M. Ike, a graduate student in the Master of Military Art and Science

Degree Program, on the following date [s]: concerning

the following topic: the Army’s doctrinal planning process.

2. I understand that the recording [s] and any transcript resulting from this interview will belong to the U.S. Government to be used in any manner deemed in the best interests of the Command and General Staff College or the U.S. Army, in accordance with guidelines posted by the Director, Graduate Degree Programs and the Center for Military History. I also understand that subject to security classification restrictions I will be provided with a copy of the recording for my professional records. In addition, prior to the publication of any complete edited transcript of this interview, I will be afforded an opportunity to verify its accuracy.

3. I hereby expressly and voluntarily relinquish all rights and interests in the recording [s] with the following caveat:

None _ Other:

I understand that my participation in this structured interview is voluntary and I may stop participating at any time without explanation or penalty. I understand that the tapes and transcripts resulting from this interview may be subject to the Freedom of Information Act, and therefore, may be releasable to the public contrary to my wishes. I further understand that, within the limits of the law, the U.S. Army will attempt to honor the restrictions I have requested to be placed on these materials.

Name of Interviewee Signature Date




\section{Bibliography}

Antal, John, LTC. "It's Not the Speed of the Computer that Counts! The Case for Rapid Battlefield Decision-making.” Armor, May-June 1998, 13.

Army Doctrine Publication (ADP) 3-0, Unified Land Operations. Washington, DC: Government Printing Office, 2011.

Army Doctrine Reference Publication (ADRP) 1-02, Operational Terms and Military Symbols. Washington, DC: Government Printing Office, 2012.

Army Doctrine Reference Publication (ADRP) 5-0, The Operations Process. Washington, DC: Government Printing Office, 2012.

Banner, Gregory T., LTC. “Decision Making - A Better Way.” Military Review, SeptemberOctober 1997.

C400 Army Doctrine and Planning. Command and General Staff Officer Course (CGSOC) Common Core, US Army Command and General Staff College, 2014. Copies available at the CGSOC Department of Tactics.

Crandall, Beth; Grome, Anna; Rasmussen, Louise (Applied Research Associates); Wolters, Heather, Ph.D. (U.S. Army Research Institute), Incorporating Army Design Methodology into Army Operations: Barriers and Recommendations for Facilitating Integration. Fort Leavenworth, Kansas: U.S. Army Research Institute for the Behavioral and Social Sciences, March 2012, B-1 to B-13.

Combined Arms Directorate, Army Doctrine Update. Fort Leavenworth, KS: US Army Combined Arms Center, 2007.

Dembowski, Richard, LTC, interviewed by author, Fort Leavenworth, Kansas, July 29, 2014.

Drucker, Peter F. The Practice of Management. New York: Harper and Row, Publishers, Inc., 1986, 121-136.

Field Manual (FM) 3-0, Operations. Washington, DC: Government Printing Office, 2008.

Field Manual (FM) 5-0, Army Planning and Orders Production. Washington, DC: Government Printing Office, 2005.

Field Manual (FM) 5-0, The Operations Process. Washington, DC: Government Printing Office, 2010.

Field Manual (FM) 5-0, The Operations Process. Washington, DC: Government Printing Office, 2011.

Field Manual (FM) 101-5, Staff Organization and Operations. Washington, DC: Government Printing Office, 1997.

Field Manual (FM) 101-5-1, Operational Terms and Graphics. Washington, DC: Government Printing Office, 1997.

Field Manual (FM) 34-130, Intelligence Preparation of the Battlefield. Washington, DC: Government Printing Office, 1994.

Field Manual-Interim (FMI) 5-0.1, The Operations Process. Washington, DC: Government Printing Office, 2006. 
Gharajedaghi, Jamshid. Systems Thinking: Managing Chaos and Complexity: A Platform for Designing Business Architecture. Burlington: Elsevier, 2006, 126-127.

Goebel, David. “Lesson Plan for Lesson O320: Planning for Brigade Operations.” O300 Decisive Action: Brigade Operations, Command and General Staff Officer Course (CGSOC) Advanced Operations Course (AOC), US Army Command and General Staff College, 2014. Copies available at the CGSOC Department of Tactics.

Harrison, Neil. Complexity in World Politics: Concepts and Methods of a New Paradigm. Albany: State University of New York Press, 2006, 33.

James, Frank, PhD, interviewed by author on August 14, 2014.

. "Lesson Plan for Lesson O399: Executing Brigade Operations.” O300 Decisive Action: Brigade Operations, Command and General Staff Officer Course (CGSOC) Advanced Operations Course (AOC), US Army Command and General Staff College, 2014. Copies available at the CGSOC Department of Tactics.

Jervis, Robert. System Effects: Complexity in Political and Social Life. Cambridge: Cambridge Univ Press, 1997, 6.

Joint Publication (JP) 1-02, Department of Defense Dictionary of Military and Associated Terms. Washington, DC: Government Printing Office, 1994.

Klein Associates, Inc., Making Decisions in Natural Environments. Alexandria: US Army Research Institute, 1997.

Klein, Gary, PhD. Sources of Power: How People Make Decisions. MIT: First MIT Press, 1999.

—_. "Strategies of Decision Making.” Military Review, May 1989, 56.

March, James. A Primer on Decision Making: How Decisions Happen. New York: The Free Press, 1994.

Mintzberg, Henry. The Rise and Fall of Strategic Planning: Reconceiving Roles for Planning, Plans, Planners. New York: The Free Press, 1994.

Morgan, Matthew, LTC, and Rasdall, Dennis (LTC, Ret), interviewed by author, Fort Leavenworth, Kansas, June 11, 2014.

Palmer, Peter J., LTC. "Decision Point Tactics and the Meeting Battle: Fighting the Enemy, Not the Plan.” Infantry, January-February 1997, 29.

Paparone, Christopher, COL. “US Army Decisionmaking: Past, Present and Future.” Military Review, July-August 2001, 52.

Shoffner, Wilson A., MAJ. The Military Decision-Making Process: Time For A Change. SAMS Monograph, US Army Command and General Staff College, 2000.

Stahl, Albert interviewed by author on August 12, 2014.

. “Lesson Plan for Lesson O319: ADM for Cerasia.” O300 Decisive Action: Brigade Operations, Command and General Staff Officer Course (CGSOC) Advanced Operations Course (AOC), US Army Command and General Staff College, 2014. Copies available at the CGSOC Department of Tactics. 